\title{
Assessment and Brain Training of Patients Experiencing Head and Facial Pain with a Distortion of Orofacial Somatorepresentation: A Narrative Review
}

\author{
Harry von Piekartz ${ }^{1,2, *}$ and Alba Paris-Alemany ${ }^{3,4}$ (D) \\ 1 Department of Physical Therapy and Rehabilitation Science, University of Applied Science Osnabruck, \\ 49076 Osnabrück, Germany \\ 2 Clinic for Craniofacial Therapy and Applied Pain Science, 7631 CP Ootmarsum, The Netherlands \\ 3 Motion in Brains Research Group, Institute of Neuroscience and Science of The Movement (INCIMOV), \\ Centro Superior de Estudios Universitarios La Salle, 28023 Madrid, Spain; albaparis@gmail.com \\ 4 Instituto de Dolor Craneofacial y Neuromusculoesquelético (INDCRAN), 28008 Madrid, Spain \\ * Correspondence: h.von-piekartz@osnabrueck.de
}

check for updates

Citation: von Piekartz, H.; Paris-Alemany, A. Assessment and Brain Training of Patients Experiencing Head and Facial Pain with a Distortion of Orofacial Somatorepresentation: A Narrative Review. Appl. Sci. 2021, 11, 6857. https://doi.org/10.3390/app11156857

\section{Academic Editors: Lidiane}

Lima Florencio and César Fernández De Las Peñas

Received: 27 June 2021

Accepted: 23 July 2021

Published: 26 July 2021

Publisher's Note: MDPI stays neutral with regard to jurisdictional claims in published maps and institutional affiliations.

Copyright: (c) 2021 by the authors. Licensee MDPI, Basel, Switzerland. This article is an open access article distributed under the terms and conditions of the Creative Commons Attribution (CC BY) license (https:/ / creativecommons.org/licenses/by/ $4.0 /)$.

\begin{abstract}
The management of patients experiencing chronic orofacial pain is a great challenge, due to the complexity of chronic pain itself, combined with an increased peripheral sensitization in the craniofacial itself. Therefore, patients with orofacial pain may present a clear distortion of the somatorepresentation after some time. In this review, the authors develop a neurophysiological explanation of orofacial distortion, as well as propose assessment and treatment options, based on scarcely available scientific evidence and their own clinical experience. The assessments of facial somatosensory, cognitive-affective and motor dysfunctions are crucial to establish the most accurate treatment; the assessment tools are described in the article. Two-point discrimination, laterality recognition and emotion recognition are altered in patients with orofacial pain. Other sensorimotor assessment tools, such as motor acuity and auditory acuity, are also explained. Finally, the authors review their treatment proposals, based on the integration of brain training techniques and biobehavioral interventions. Somatosensory reintegration (tactile acuity training), facial emotion recognition, movement representation techniques, orofacial motor training and therapeutic patient education are explained in detail, and this may challenge new directions in rehabilitation and research.
\end{abstract}

Keywords: orofacial pain; facial distortion; chronic pain; brain training; motor imagery; emotions recognition; orofacial exercise; laterality discrimination

\section{Introduction}

Orofacial pain (OFP) has a prevalence of $10 \%$ to $15 \%$ in the adult population [1,2] is one of the most common causes of chronic pain after back, neck and knee pain [3,4]. More women than men reported orofacial pain (odds ratio $2.58,95 \%$ confidence interval (CI) 2.48-2.68), and there was a significant increase in the prevalence of reported pain from 2010 to 2017 in both women and men and women were at higher risk of both developing orofacial pain (incidence rate ratio $2.37 ; 95 \%$ CI 2.25-2.50) and reporting pain in consecutive check-ups (incidence rate ratio 2.56 ; 95\% CI 2.29-2.87 [5].

The definitions of "orofacial pain (OFP)" and "headache" are based on anatomical landmark definitions [6]. Facial pain is defined as pain occurring mainly or exclusively under the infra-orbitomeatal line, anterior to the pinnae and above the neck, which includes temporomandibular joint pain; headaches are defined as pain dominantly above the orbitomeatal and/or nuchal ridge [6,7]. Recently, it has to be suggested upgrading the anatomical landmark for facial pain upwards to the orbitomeatal line [8]. This kind of anatomical classification regularly debated in the literature because orofacial pain (OP) cannot be separated from established headache forms, such as migraine-type and tension-type 
headaches (TTH) [9]. The clinical diagnoses of Axis 1 a Athrogenic TMD or Dentoalveolar Pain [10] versus Migraine with Aura [7] are well described and easy to detect clinically within these definitions in contrast to chronic orofacial pain (COFP), whereby $60 \%$ of patients also report having a form of headache [11]. This is supported by observational studies, which suggests clear comorbidity of chronic head-face-TMJ and neck pain [12]. From a pathobiological perspective, the strong overlap of COFP and headaches may be supported by the neuronal interplay of the trigeminal cervical complex in the brainstem and neuro-hormonal plasticity, which manifests itself in reaction to persistent injury and pain experiences $[13,14]$. Moreover, the head and the face are innervated by the trigeminal nerve cortex and connectomes (comprehensive map of neural connections in the brain) and in the somatosensory cortex an intimate overlap of these regions. are observed [15].

An acceptable definition of COFP is still being debated. One reason for this is the influence of non-biological (psycho-social-emotional) factors, which negatively affect the quality of life manifest by COFP [16]. Therefore, threat and catastrophizing anxiety disorders, changes in self-efficacy and sleep disturbance are strongly comorbid with COFP [17,18]. One aspect that is less emphasized in the literature is the pattern of somatosensory distortion during long-term trigeminal sensitivity that affects classical headaches and COFP [19].

Evidence supports the presence of a dysfunctional pain pattern in patients with COFP, which presents with abnormal processing at the central nervous system [19], hyperexcitation and neuroplastic changes that would be part of the central sensitization phenomenon [20]. Characteristics such as generalized mechanical hyperalgesia (head-faceneck but also other body areas), alterations in pain modulation, increased expansion of pain areas and presence of associated psychological factors are in line with the process of central sensitization and are usually found in COFP patients [21,22].

\section{Dysfunctional COFP}

The onset and persistence of head and face pain can be related to an impairment in the reception and processing of the nociceptive stimuli and the central nervous system (CNS) $[22,23]$. During long-term peripheral facial nociception, such as TMD pain, odontalgia and post-face-trauma changes of brainstem and CNS circuits emerge, which may lead to altered facial pain [24]. Patients who present with an altered or dysfunctional pain located in the head and face areas may associate several dysfunctions, such as somatosensory, motor, cognitive and emotional, with the abnormal central nervous system processing [25]. A bio-psycho-social matrix model for orofacial musculoskeletal pain have been proposed to explain the relation among the different factors that are implicated in these patents' pain experience. Psychological burdens may have a negative impact on the functioning of the autonomic nervous system, mood regulation, pain inhibitory system and emotional motor system [26].

It is conceivable that the alterations of CNS lead to changes at the sensory (S1) and motor (M1) cortex, which represents the face region; thus, it will be sensitized and disinhibited (lack of inhibition, which leads to activation) by pain [27]. Motor changes may be due to central and peripheral mechanisms. Some studies have identified structural and functional changes in motor cortical areas of patients with pain [28,29]. Interestingly, motor areas can be influence by emotions, as seen after the exposure to an adverse cognitive or emotional stimuli by the activation of supplementary motor area [30]. The same activation of the SMA has been found in catastrophic TMD patients [31]. The SMA contributes to the movement planning process. It is theorized that the pre-activation found in these patients could be due to avoidance or anticipatory motor behaviors [32].

The cortical disinhibition, together with the central sensitization, present in chronic pain, also drives changes in primary sensory areas and leads to perceptual disturbances [33]. It has been demonstrated that COFP presents with altered epicritic sensibility, due to the presence of reduced tactile acuity [34], altered tactile detection threshold [35] and worse laterality discrimination [36]. Furthermore, proprioceptive and non-proprioceptive alterations, which are manifested through body, perceptual distortions [37] and disturbances 
of internal and external emotions recognition, have been found in these patients [38,39]. All of these changes support the concept of cortical reorganization that is hypothesized to occurs in chronic pain patients [33].

\section{Motor and Somatosensory Disturbances in COFP}

As said earlier, somatosensory alterations in terms of epicritic and discriminative sensitivity are present in COFP patients. Normal tactile acuity depends on a competent epicritic sensory system and an adequate central processing of the efferent signals. For example, in chronic neck [40], low back pain [41] and complex regional pain syndrome [42], activity levels are changed in the somatosensory cortex (S1). In comparison with healthy subjects, TMD patients suffering from myofascial pain have a decreased S1 grey-matter volume as defined by structural MRI, which may be expressed in a reduced sensory function [43], supported by the results obtained at the two-point discrimination test, which indicates a decrease in the discriminative threshold [34]. Tactile acuity depends strictly on the correct functioning of the somatosensory system; thus, the two-point discrimination test has been suggested as a good assessment tool to evaluate S1 area and the somatosensory function [34].

Another aspect found related to the altered somatosensory system is the auditory acuity, which consists on the localization of sounds, pitches and muting of background noises [44]. This ability may be "blurred" during chronic pain, since there are sensory convergence points at the thalamus and brainstem centers, such as the locus coeruleus. This can lead to difficulty at discrimination of different noises, hyperacusis and tinnitus $[45,46]$. Clinically it is observed that in face-pain auditory acuity disturbances appears together with changes in tactile acuity and a left/right judgment task [47].

Reduced accuracy and prolonged response time in patients with head and face pain when performing the laterality judgment task have been found [48-50]. Laterality recognition or left/right judgment is the ability to recognize that a part of the body belongs to the left or the right side of the body; it is needed for conscious access to the content of the intention of a movement, which is usually performed unconsciously during a normal motor planning process of the movement preparation [51,52] and differs from motor execution, which is related with the (pre)motor cortex [53]. To be able to judge the laterality of a picture it is believed that the subjects mentally needs to rotate an internal representation of their own body part examined to mentally match it with the presented one. This process, therefore, would be influenced by the motor and somatosensory areas, in terms of recognition of the position of the body parts in space (proprioception) and the visual stimuli [54]; indeed, when the laterality discrimination is in conflict, it may be associated with a distorted proprioception cortical scheme of the body [55]. In fact, neural activity has been found in the sensorimotor, posterior parietal and occipital areas during the lateral recognition task [56]. Moreover, the activity of the superior precentral sulcus and intraparietal sulcus areas, predominantly on the left, were associated with accuracy of the imagery task performance [57]. All of these findings help to explain what could be happening at the CNS when performing tasks that relay on implicit motor imagery.

Finally, it is important to mention that motor control disturbances are frequent in COFP patients. Face pain or induced nerve blocks or (long-term) anesthesia of the oropharynx may be associated with impaired facial motor, tongue and larynx function expressed by impaired facial expression, speech and swallowing, which may be associated with changed facial motor cortex neuroplasticity [58]. To be able to perform an accurate movement, precise sensory information is required for an efficient and adaptive motor function [59]. In this line, activity at primary sensory and motor areas, parietal operculum, anterior and posterior cerebellum, caudal premotor areas and fronto-parietal areas has been found related to movement execution [57]. Somatotopic, peripersonal and spatial sensory data are integrated into a dynamic neural representation, which conforms the physiological body schema and permits the control over every body part and therefore movement or navigation in space $[60,61]$. Motor control disturbances found in patients with a TMD have been 
described as reduced muscles efficiency, altered chewing movement during mastication and swallowing performance [62-64]. The reduced efficiency has been identified together with a reduced bite force in patients with pain $[62,65]$. Regarding the chewing pattern, it is frequent that patients with TMJ pain present a chewing side preference, though leading to the presence of a unilateral masticatory pattern $[66,67]$, which has also been related to the absence of lateral jaw movement during chewing on the unaffected side; thus, the physiological rotation movement of the mandible cannot be performed [63]. Other motor control disturbances that can be found associated to masticatory pain are the ones related to the head movement during the mandibular function, showing an abnormal increased range of craniocervical movement associate to mouth opening and chewing [68].

\section{Orofacial Somatorepresentation Distortion (OFSD)}

Perceptual distortions of the body schema demonstrate the presence of a somatosensory system disturbance [33]. The primary somatosensory cortical activity is involved not only in shaping our somatosensation but also in the perception of our body dimension [69]. Healthy subjects exposed to a recognition of ones' own face task tend to overestimate the lower part of the face while underestimate the upper part of the face, with an asymmetrical representation of the face size [70]. The sense of face identity can be manipulated by nerve blockage and painful stimulation, which generate a face distortion with a feeling of swelling together with loss of tactile sensitivity in healthy subjects [71,72].

It seems characteristic among patients with COFP the presence of facial perceptual distortions, reporting perceived swelling and enlargement of the painful area [37]. Although there is limited evidence regarding this topic in COFP, in other chronic pain conditions, it has been well described. Patients with chronic back pain or complex regional pain syndrome perceive their painful area differently from its real appearance [73,74]. The mechanisms underlying these altered perceptions are still unknown; however, it is speculated that cortical reorganization is underneath this process [75].

As of the time this was written, no association has been found between the face perceptual distortion and psychological variables (anxiety, catastrophizing and depression) with the exception of dissociative symptoms [37]. More research is needed in this field.

\section{Cognitive and Emotional Disturbances}

Basic emotions are defined as happiness, fear, disgust, anger, surprise and sadness [76]. Patients with COFP seem to have an altered emotions recognition accuracy, they perform worse at the facial emotion recognition task $[77,78]$. These findings underline a possible emotional dysfunctional processing. In both studies [77,78], COFP patients' incorrectly identified the faces representing sadness and fear, as anger and fear were miss identified as disgust.

Humans activate brain networks in charge of their own actions, sensations, and emotions whenever witnessing the actions, sensations, and emotions of others [79]. Those brain areas include the insula, inferior frontal gyrus and medial frontal regions around the cingulate cortex, as well as the amygdala, thalamus, putamen, caudate and primary somatosensory area [80,81]. Interestingly it has been observed that the activity in these networks is stronger in more empathic [79] and reduced in psychopathic individuals [82], leading many to suspect this network is what is causing us to feel what others feel.

Brain areas implicated in emotions recognition have been determined through the observation of patients with brain lesions and their performance at the emotion recognition task [81]. That is how, nowadays, we can assume that the integrity of several structures, such as the thalamus, primary somatosensory area, right motor cortex, inferior frontal cortex, prefrontal region and orbitofrontal regions, is crucial for the emotions recognition [83-87]. In addition, the insula and the amygdala have been suggested to be particularly important for associating emotional recognition of anger, sadness, surprise and happiness, with the amygdala being more specific for the fear, and the insula more specific for disgust [88-91]. 
Accurate and fast facial emotional recognition stimulates a response to mimic the facial expression with their own facial muscles, which is called the reflex of "facial mimicry", followed by activating the emotion-neuro-endocrine neuromatrix [92-94]. Hence, it is suggested that neural motor and limbic networks participate in facial expressions and recognition [95], in addition to bottom-up (sensory signals from the visual system) and top-down (cognitive control through affective evaluation) information processing [91,96].

It is suggested that the emotional recognition (observation) and facial expression (execution) of emotions may share a representation structure at the pre-supplementary motor cortex and at the superior/medial temporal gyrus [95]. The loss of the basic ability to recognize mimicry-coded basic emotions can lead to misunderstandings, limited empathy and insecure social behavior $[97,98]$.

\section{Consequences of the Sensorimotor and Emotional Disturbances in COFP}

The alteration of the external and internal emotions recognition, laterality discrimination and body perception may conform part of the somatosensory distortions present in COFP patients. Emotion-generating regions of the brain are interconnected and are involved in motor, sensory and cognitive functions to make possible the face somatoperception and somatorepresentation $[99,100]$.

COFP patients usually present with reduced facial movements due to the presence of pain. In this line, it has been observed that the inability to express feelings with mimics may interfere in the ones' own recognition of emotions [92]. A recent study has found a moderate-to-strong association between face and head pain and alexithymic features [101]. Alexithymia is a personality trait based in an intrinsic difficulty in recognizing the emotional components of subjective experiences (emotion recognition and expression) [102]. Patients with alexithymia suffer from higher psychopathological distress [103], and it is often stated in connection with chronic pain syndromes [104]. Therefore, it seems to be an important contributing factor in the development of a chronic facial pain [101]. Causes of alexithymia are unknown. Presumptions go towards neurobiological causes, such an interruption of the connection between the limbic system and parts of the thalamus which have also imbedded the brain neuromatrix of emotional experiences $[105,106]$.

In patients with somatoform disorders, it is suggested that the presence of a deficit of facial emotion recognition is a consequence of the concurrent alexithymia [107]. Another psychological feature related to an altered facial emotion recognition is body dysmorphic disorder, characterized by distress about imagined or slight appearance flaws [108]. In this line, an alteration in familiar face recognition, (prosopagnosia) may be altered in migraine patients [109]. In some patients with COFP, a concomitance of alexithymic features and somatization have been observed, as well as an association with the presence of a deficit at emotions recognition, together with a reduced right/lateral discrimination acuity [77,78].

Actual structural changes in brain structures have been described in chronic myofascial temporomandibular pain. An increase in gray matter of the limbic areas and decrease in the pons could represent trigeminal and limbic dysregulation [43]. In chronic-pain conditions, learning-induced functional and structural brain changes involving sensorimotor, limbic and frontal areas are crucial [110]. Those brain changes are also found in emotional disorders. Altered psychological status are frequent in chronic pain patients $[110,111]$. It may be assumed that the disturbed somatorepresentation in orofacial pain negatively affects the quality of life and leads to an individual pain state characterized by a feeling of isolation; loss of self-identity and social relations; and hopelessness, resignation, and a lack of faith of recovery and in a chronic orofacial [16,112-114].

\section{Clinical Assessment}

The assessment of a patient on OFSD should be based on the multidimensional paradigm of physical therapy that comprises several dimensions: sensorial, cognitiveaffective and motor (Scheme 1). For the management of a patient with face and head pain with a possible somatorepresentation distortion, the focus of the assessment will be placed 
at the somatosensory dysfunction assessing pain, face perception, tactile and auditory acuity and laterality discrimination; in this way, a picture of the functioning of the sensory system and the ability to integrate the information will be obtained. In the second term, the cognitive-affective and motor-dysfunction dimensions may be assessed, on the one hand, through emotions recognition and motor acuity, and on the other hand, through several questionnaires. Motor acuity will add information about the motor dysfunction that, in many cases, is associated with the somatosensory dysfunction. Craniocervical motor control, tongue strength and the masticatory pattern will confirm the motor assessment. The questionnaires that are of special interest are the following: the Craniofacial Pain and Disability Inventory (CF-PDI) will tell the grade of disability and pain, the Toronto Alexithyma Scale 26 (TAS-26) will grade the alexithymic features and may serve as a predictor and the Tampa Scale for Kinesiophobia for Temporomandibular Disorders (TSKTMD-S) will help to stablish the best approach for the patient. A patient with high levels of Kinesiophobia for example will need an assessment and management based in movement representation techniques without movement execution. This is one reason to start with appropriate questionnaires, getting an impression of the individual patient. Following it is the proposed protocol for clinical assessment (Sections 7.1-7.6):

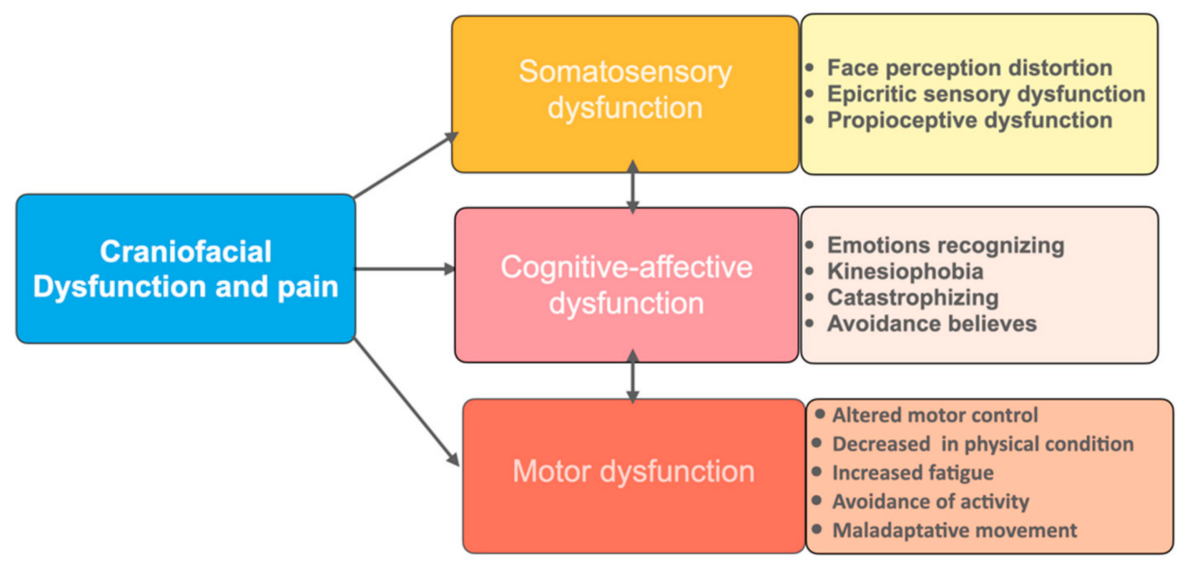

Scheme 1. Dysfunctional dimensions of craniofacial pain and their associated dysfunctions/distortions.

\subsection{Questionnaires}

7.1.1. Craniofacial Pain and Disability Inventory (CF-PDI)

It consists of 21 items and two subscales: "pain and disability" and "jaw functional status". High internal consistency of the CF-PDI (Cronbach's $\alpha: 0.88$ ) and of the two subscales (Cronbach's $\alpha$ : 0.80-0.86) was confirmed. It also demonstrated excellent testretest reliability (ICC $=0.90 ; 95 \%$ confidence interval $[C I] 0.86-0.93$ ). The SEM and MDC were 2.4 and 7 points, respectively [115]. It was firstly developed by La Touche et al., in Spanish, but is has been translated and validated into many other languages [116-119].

\subsubsection{Toronto Alexithymia Scale 26 (TAS-26)}

It is a subjective self-evaluation questionnaire with 26 items that allows for the depiction of alexithymic features. The items response is based on a five-point Likert scale. The sum score of the TAS-26 determines the extent of alexithymia, which is classified in three subscales. Therefore, it allows for differentiating which of the three characteristic aspects of alexithymia (difficulty in identifying emotions (scale 1), difficulties in describing emotions (scale 2) and externally oriented thinking style (scale 3)) dominate. It has demonstrated good internal consistency (Cronbach's alpha $=0.67$ to 0.84 ). A participant is diagnosed with alexithymia when a score of 30 and higher is recorded [120]. 


\subsubsection{Tampa Scale for Kinesiophobia for Temporomandibular Disorders (TSK-TMD-S)}

It is an instrument to assess fear of movement in TMD patients. It has been translated into several languages [121-123] but was firstly developed and validated in Dutch [124]. This version is composed of 12 items and two subscales: activity avoidance and somatic focus. This two-factor solution of the Dutch TSK-TMD has generally good reliability and convergent validity [119]. When the validation to the Spanish was performed, the statistics reduced it to 10 items, probably due to language differences [121].

\subsection{Individual Face Perception (IFP)}

Getting an impression of the personal (face) perception, "body scanning" of the face, head and a "subjective body(face)chart". Body scanning is dominantly focused on perception on internal bodily sensation ("interoception"). Interoception has been defined as the sense of the physiological condition of the body [125], including the perception of temperature, itch, muscular and visceral sensations, hunger, thirst, pain and other physical symptoms [126]. The clinician may instruct the patient to systematically describe his/her perception of the different localizations of the face and top and dorsal of the head if necessary. The subjective perception may be divided into the (a) quality (dull, sharp, smudged, etc.) and (b) intensity, which may be registered by a Subjective Sensitivity Scale (SSS) where numbers are subclassified: very unclear weak, moderate clarity/intensity of sensation and very clear intense sensation (Figure 1) [127]. In the meantime, an impression of mental dysfunction, such as fear (avoidance), catastrophizing and depression, may be exposed [128].

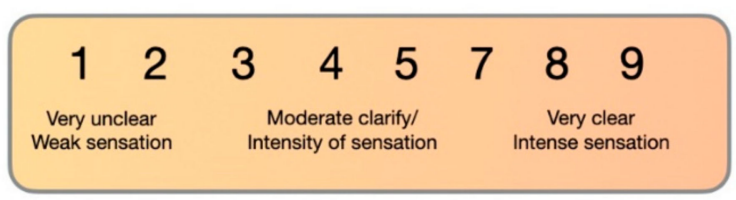

(a)

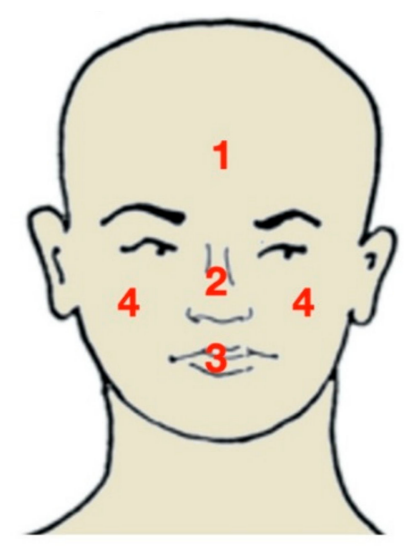

(b)

Figure 1. Individual face perception assessment. (a) Subjective Sensitivity Scale (SDSS) used during body scanning. (b) The subjective body (face) chart where the face is divided into 4 regions, defining the magnitude and localization of the face perception changes (modified after Fox et al., 2012).

The subjective body(face) chart helps define the magnitude and the localization of the changed perception during the body scan, where the patient has to paint the affected face or head area, which may be extremely useful during external touch tests, such as two-point discrimination and reassessment after intervention [129].

\subsection{Two-Point Discrimination}

The two-point discrimination test is performed with an esthesiometer to assess tactile acuity. The initial distance between the two points should be established at a distance of $40 \mathrm{~mm}$. It is needed to apply both stimuli at the same time, with enough pressure to sink into the skin during $1 \mathrm{~s}$. The position of the two points should be changed after each stimulus. The minimal discrimination distance would be found after three correct responses of discrimination. The distance between the points should decrease or increase in $5 \mathrm{~mm}$, and subsequently $1 \mathrm{~mm}$. The patient is asked to give one of the following replies after the application of the stimuli: " 1 ", if they felt only one stimulus; " 2 ", if they felt two 
stimuli; and "I don't know", if they were not able to discriminate 1 or 2 , which is also considered incorrect. The reliability of this procedure is considered good/moderate [34] (Figure 2).

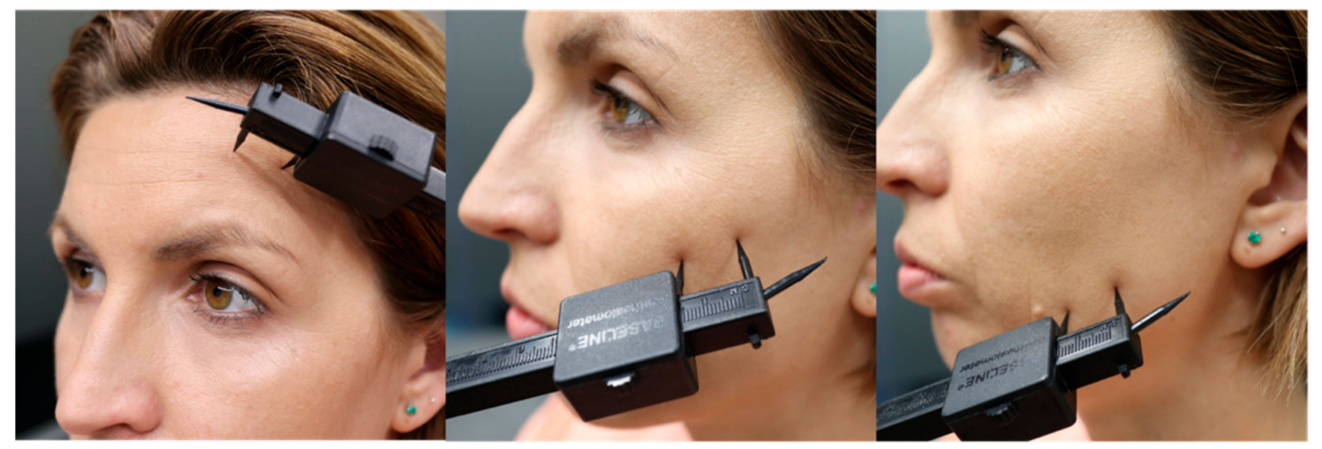

Figure 2. Two-point discrimination assessment. Measuring at V1, V2 and V3 areas.

\subsection{Laterality Discrimination}

Left/right judgement is a task where the patient has to identify pictures where the model activates the eye, tongue, eyebrow or jaw as moving on or towards either the left or right side of his or her face as soon as possible [50] (Figure 3). Accuracy (\%) and average response time (seconds) can be measured. Images may be displayed for a maximum of $5 \mathrm{~s}$ each, before the next image was shown. Images were randomly rotated at $0^{\circ}, 90^{\circ}$, $180^{\circ}$ or $270^{\circ}$. That is, $25 \%$ were orientated upright, $25 \%$ were upside-down, $25 \%$ were rotated $90^{\circ}$ to the left and $25 \%$ to the right. Lateral accuracy between $60.67 \pm 19.21 \%$ and $89.60 \pm 22.99 \%$ and reaction times ranging from $1.77 \pm 0.71 \mathrm{~s}$ to $4.84 \pm 1.48 \mathrm{~s}$ have been described in healthy subjects $[49,130]$. Reduced accuracy and slower reaction times among chronic face and head patients have also been found $[36,48,49]$.

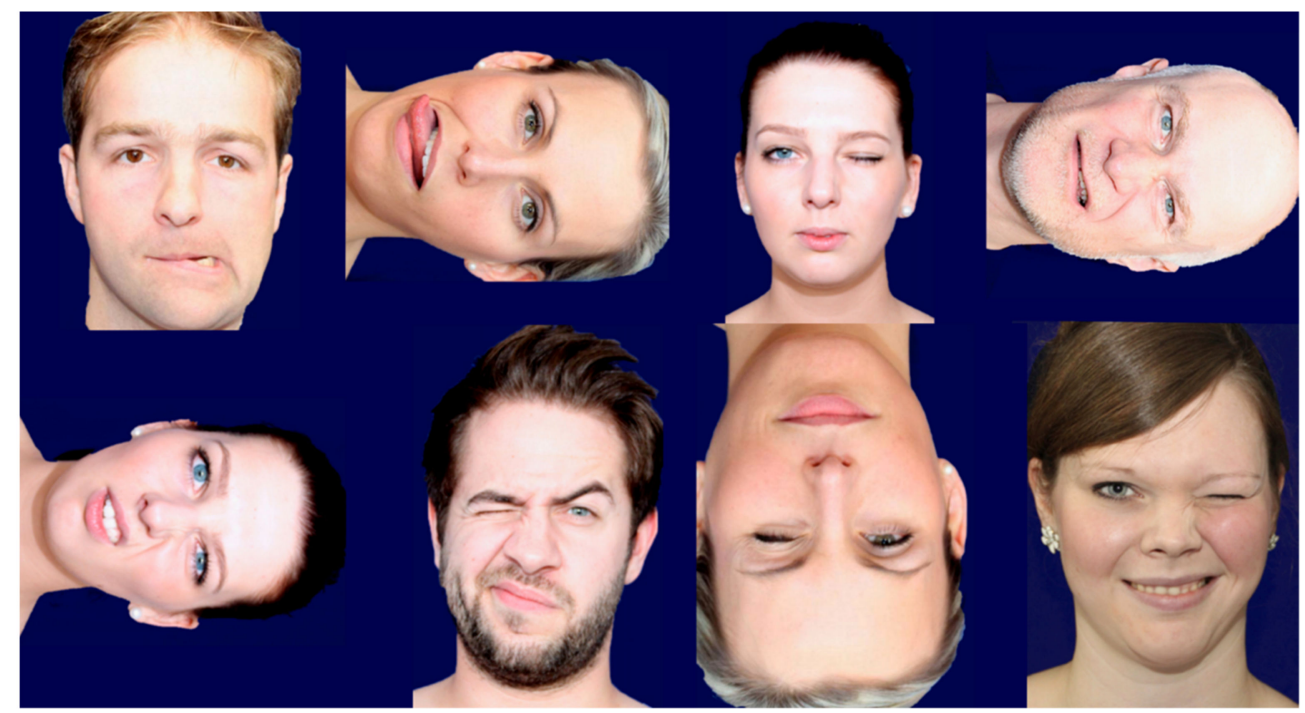

Figure 3. Left/right judgement is a task identifying randomized pictures where the model activates the eye, tongue, eyebrow or jaw as moving on or towards either the left or right side in a rotated position of $0^{\circ}, 90^{\circ}, 180^{\circ}$ or $270^{\circ}$.

\subsection{Emotions Recognition}

According to the authors, the three tasks most used in clinical research and the clinic for the measurement of emotion recognition are the following:

- $\quad$ Reading the Mind in the Eyes Test (RMET) is a test based on facial mimicry that includes 36 photographs of male and female eyes depicting emotional states. For each photograph, participants are asked to choose the emotional state that best describes 
the eyes, choosing between one of four possible emotions. In the present study, the performance of the participants was calculated as the number of correct responses divided by the total number of trials [131]. The internal consistency for the sample of our study was acceptable (Cronbach's $\alpha=0.67$ ) [132].

- The Facially Expressed Emotion Labeling (FEEL) test is a computer-based test measures one's ability to recognize facially expressed basic emotions. The stimuli which the subject has to recognize consist of 42 photographs showing facial displays of six basic emotions which are presented on a computer screen for $300 \mathrm{~ms}$. The test is reliable and has good internal consistency (Cronbach's coefficient alpha of $r=0.76$ ) [133].

- Myfacetraining (MFT-CRAFTA) software that can be used as assessment and intervention for PC and other devices. The principle is the same as for the FEEL Test (https: / / www.myfacetraining.com, accessed on 20 June 2021).

The authors have experienced that the RMET is a simple and cheap test, but its duration is relative long (15-20 $\mathrm{min}$ ), and it is restricted to recognition of the upper face and does not test the basic emotion but the emotional intelligence. The FEEL and TMF test all six basic emotions in the same way. The FEEL test regenerates a FEEL score (a number for the combination of the average accuracy and speed), but the software is only functioning on Windows software. The TMF-CRAFTA also has a L/R recognition and a (digital) mirror program and is usable on all devices but is not validated on internal inconsistence. Further it has different tools for rehabilitation, such as isolated muscle and graded emotion training with(out)mirroring.

\subsection{Motor Acuity}

\subsubsection{Craniocervical Motor Control}

Assessment of the presence of an abnormal movement of the head during mouth opening, mastication and swallowing. The disturbed movement patterns to identify are head protraction and large craniocervical extension when performing the ahead mentioned tasks [134].

\subsubsection{Masticatory Test}

The unilateral mastication test is a direct observation method for the identification of the habitual mastication side in case of a unilateral mastication pattern. With a chewing gum, and after 7 cycles of $15 \mathrm{~s}$ of mastication, the position of the gum is registered. If the patients accumulate five or more times, the gum at the same side is classified as unilateral masticator [135], which has been associated to unilateral sensorimotor modifications [136]. A second variable to assess during the mastication test is the dentification of the absence of homolateral movement of the jaw towards the chewing side. It is frequent to find abnormal masticatory movements in TMD [65].

\subsubsection{Tongue Function}

Tongue strength and endurance can be measured with the device called IOPI (Iowa Oral Performance Instrument; Northwest, Co., LLC, Carnation, WA, USA) [137]. The tongue is positioned towards the palate with a plastic bulb in between to offer the pressure exerted by the tongue. The maximal strength in $\mathrm{KPa}$ and the seconds able to maintain the $50 \%$ of the maximal strength are the values to register. Altered tongue performance has been associated to masticatory and swallowing disturbances in TMD patients [138].

\subsection{Auditory Acuity}

In the auditory discrimination performance localization, distance, frequency $(\mathrm{Hz})$ and intensity $(\mathrm{dB})$ may be measured by a special loudspeaker or a validated android-IOS based app with a variable frequency $(250-8000 \mathrm{~Hz})$ and intensity $(5-49 \mathrm{~dB})$ [139]. The purpose is to observe if there are differences in auditory perception of these parameters in the symptomatic peripersonal space vs. the healthy. Clinical observation shows that during a unilateral orofacial somatorepresentation distortion for example in trigeminal neuropathy 
difference in distances and sounds with a high frequency (larger $4000 \mathrm{~Hz}$ ) are less recognized (Figure 4). Special the higher frequency may influence patient pain experience and facial motor function. According to the literature and the authors' knowledge, no reference values and further studies are known in this domain.

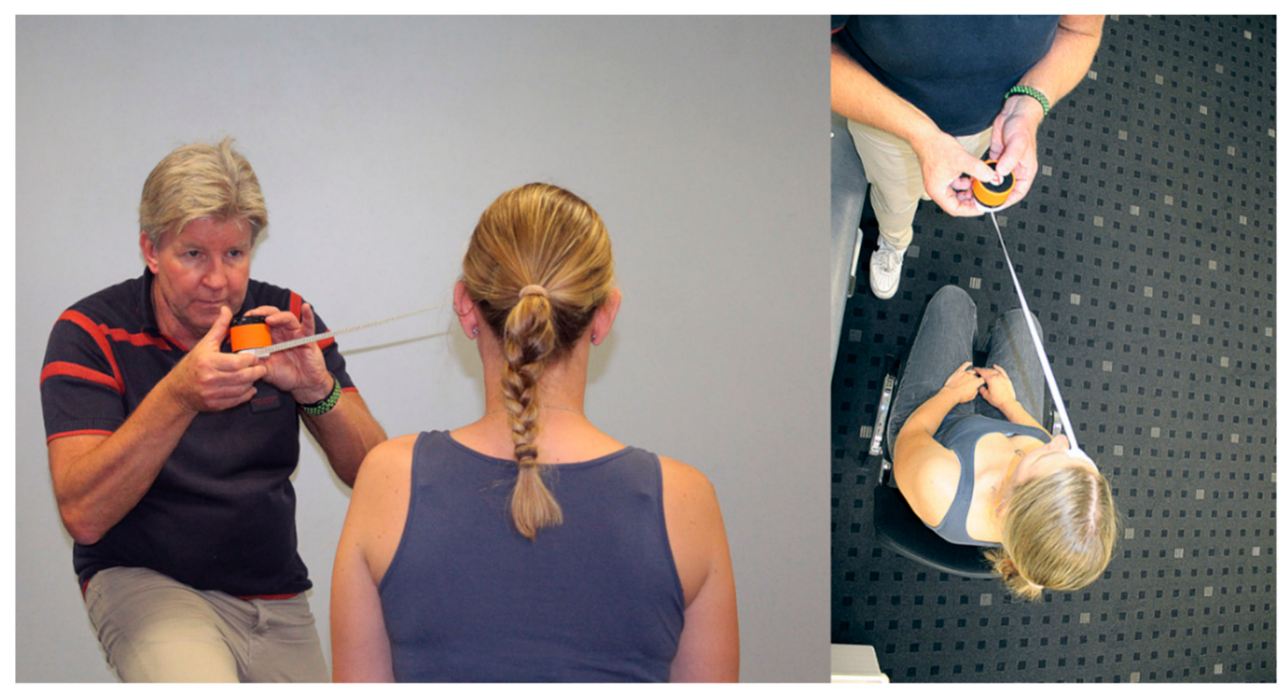

(a)

(b)

Figure 4. Assessment of auditory acuity. (a) With a loudspeaker with variable frequency $(250-8000 \mathrm{~Hz})$ and sound intensity $(5-40 \mathrm{~dB})$, it is possible to measure in different regions of the peripersonal space. (b) With a centimeter of light fixed on the head with a piece of tape, distances in space can easily be recorded.

\section{Brain-Based Intervention Strategies}

\subsection{Somatosensory Reintegration}

The skin of the face has a great number of free nerve endings ( $\mathrm{C}$ and $\mathrm{A}$ delta fibers) and mechanoreceptors and a high density of A-beta fibers. These permit a low threshold to thermal, mechanical and noxious stimuli, as well as a high tactile detection, localization and discrimination ability $[140,141]$.

The sensory information is transmitted and filtered before it reaches the cortical areas of the brain. Thus, the transmission of irrelevant sensory information is inhibited. However, when a threshold is surpassed in terms of intensity of the stimuli or differs from the expectations, the attention is shifted towards that location [142]. In this situation, the executive cortex becomes involved to modulate the response. In patients with a perceptive distortion, the sensory system is not processing in the best manner, and their attention is directed to the altered body part where the perception is being felt [143]. Together with the sensory dysfunction, the task performance is altered, supporting altered executive functions and possible changes in the functional connectivity at the SNC [55].

As it has been demonstrated in patients with chronic pain, an altered activation of the cortical and subcortical structures, in terms of a lower activation of the inhibition and attention areas and increased activation in other areas [144], interventions that will generate an influence over this structures and functions seem interesting.

Changes in perception and activation of brain areas have been demonstrated, from the rubber hand illusion until the third thumb experiment, where a cortical integration of the extra thumb achieved activation of neural pathways due to the fake thumb, leading to a neuroplastic process of the SNC reaching a greater body representation [145]. In this way, the combination of sensory and visual stimuli seems an interesting option to generate neuroplastic changes, based in an attentional intervention where the tactile stimuli will be integrated together with the visual feedback [146,147]. It has been demonstrated that multisensory stimuli application improves pain, tactile acuity and face distortion $[146,148,149]$. 
On the other hand, it is important to point out that the training of discriminative stimuli should be included in the sensory reintegration intervention [150]. The sensory retraining to achieve sensory reintegration is based on the theory of the cognitive-behavioral approach, where the patient learns to ignore or blot out the unpleasant orofacial sensations and normalize the cortical reorganization enhancing the neuroplasticity [151], therefore improving the somatorepresentation. What is needed is the competence of the sensory system to feel sensations and the integration of them by means of the sensory and motor integrations, as well as cognitive areas implicated at the recognition of emotions or recognizing of objects [100].

\subsection{Emotions Representation}

The preceding data support the idea of alexithymia being a characteristic trait present in COFP patients that predicts the presence of a dysfunctional facial emotional recognition $[72,147,148,152,153]$. The identification of alexithymia is an interesting way to predict and follow the dysfunction at the emotions recognizing task. Training of the emotions representation may be accomplished through the emotions-recognition task and through the practice of the facial expressions.

The task of emotions recognition is characterized by the recognition through the visual field the perception of an observed movement that needs to be integrated together with the limbic system (memory and emotions). On the other hand, there is a mirror neurons system that is activated when identifying a face movement; however, the implication of the limbic system is greater if the face movement is the expression of an emotion. This leads us to think about the empathy needed to socialize. Indeed, the observation of a facial emotion is more than an action observation due to the cognitive and limbic process that is underneath $[84,86]$.

The training through a cognitive behavioral approach and activation of cortical mirror neurons and limbic areas may improve the emotions recognition task, leading to a relearning and improving acuity at discrimination of emotions. The pain itself could be a negative influence over the SNC. With respect to the literature, the authors are not aware if the improvement of pain will also improve the emotional recognizing without a specific intervention, or if the intervention with the task is what would help with pain reduction. This is a recent topic under research and there are still many gaps to fill in the following years.

When doing a facial emotion-recognizing task, the patients may activate his/her own motor areas as it happens during the empathy process [154]. It is a social tool that permits people to interact, and it has been reported that mirror neurons system is necessary to be able to recognize others' emotions, as well as to put yourself in someone else's shoes. In this way, our brain mimics the expression that is observed and perceived, and also motor cortical areas that will perform the facial expression of the emotion become activated. This is a basic explanation for what is happening when observing a sad person and our own face expression changes to a sad expression, and why, when we see someone laughing, we also laugh. It is the motor response through mirror motor neurons system combined with the limbic integration [155]. Training of the motor aspect of the emotional expressions could also help reduce pain and improve cortical reorganization, since they share affect-specific networks with perception of facial expressions [81,95].

\subsection{Movement Representation Techniques}

The representation of a movement is a complex process that starts with the intention and planning of a movement which is usually performed unconsciously and relies on perceptive and cognitive processes [156,157]. Through the movement representations techniques, neurophysiological responses are evoked, such as activating the cortical motor networks and improving cortical organization [158-160]. The so-called "Graded Motor Imagery" is confirmed by three steps: left/right training, imagine movements and mirror therapy $[50,161]$. 
The included strategies among the movement representation techniques are motor imagery, action observation training and visual mirror feedback therapy [162]. The movement representations based on motor imagery can be described as implicit or explicit. Explicit motor imagery is based in the mental reproduction of a movement visually (from first person view or third person view) or kinesthetically. Implicit motor imagery makes reference to the mental process to make judgments or decisions as when identifying to what side corresponds to a body part shown. It seems that, to give an answer, a mental rotation of our own body part must be performed. This process can be performed through laterality discrimination tasks as in the right/left judgment. However, some controversy surrounds this topic, and it is hypothesized that we may need not only the mental rotation but also some other spatial and contextual information to be able to emit the correct judgment $[56,163]$.

Action observation is based on the observation of another one's movements in a recording or in real life. Motor imagery (explicit) and action observation both activate similar cortical areas; however, motor imagery also activates subcortical areas, as happens with the real movement execution [164]. On the other hand, action observation has been compared to visual mirror feedback therapy, and a different activation of brain areas has been obtained, concluding that different neural processes are implicated in each of them $[165,166]$. The visual mirror feedback therapy consists of observing the movement that is being performed with a focus over motor cues, such as "pay attention to the jaw movement to the right". There is evidence of the effects of this techniques for pain reduction, improving range of movement and strength [167-170].

When proposing a protocol based on movement representation techniques, there are several facts to take in mind. The first one is that the ability of motor imagery is reduced among patients with chronic pain [171] and can be assessed with the Motor Imagery Questionnaire (MIQ) [172]. In a more practical way, if the patient is having problems with the mental task of imagining the movements, the action observation training will be a better option to start with instead of motor imagery. Another fact to have in mind is the possibility of generating mental fatigue with a movement representation training; that is why the dose should be adjusted and assessed with a fatigue scale scoring 0-10 after the full training, to adjust the dose of series and repetitions.

If the patient must train a new movement or a movement that is dysfunctional, the $\mathrm{AO}$ will be better because of the external referent that will be offered. The inclusion of $\mathrm{AO}$ and MI to the real movement execution enhances the results for strength. Thus, we propose to start doing the movement representation of the exercises with motor imagery or action observation and then doing the execution of them: one series of the imagined (or observed) exercise, followed by one series of the executed exercise. The real performance of exercises can be integrated with the visual mirror feedback, which involved doing them in front of a mirror, focusing on the correct movement pattern. These movement representation techniques, combined with the movement execution, obtain better results in regard to motor learning [173].

Training based in movement representation may provide an opportunity to restore body image disruption, reduce pain and improve motor function in a systematic (clear described duration, frequency a day, weeks) way. There is some strong evidence, for example, in chronic regional pain syndrome of the shoulder and back pain, that pain neuroeducation, together with systematic movement representation techniques, can strongly affect pain and increase activities [174]. There is little research available relating to patients with face pain. There are few interventions described for the orofacial region, based on lateral recognition, motor imagery, action observation and visual mirror feedback therapy; thus, this topic needs more research among COFP $[50,175]$.

\section{Treatment Proposals}

In the following, the authors describe the interventions, in their opinion, for a patient to obtain great improvements based on the available evidence. All the interventions are 
structured and aimed to influence the patients' brain to generate a new cortical reorganization. The treatment focuses on several strategies to improve somatorepresentation, movement representation and movement execution. Facial training (facial recognitionimagery-expression) includes specific tasks for facial sensorimotor system which may be integrated in this proposed protocol [50].

There are two main strategies, namely brain training and biobehavioral interventions (Scheme 2), and four main aspects on the treatment protocol: somatosensory reintegration (tactile and discriminative), movement representation techniques, therapeutic exercise (motor training) and therapeutic patient education (to reinforce the other interventions from a behavioral point of view).

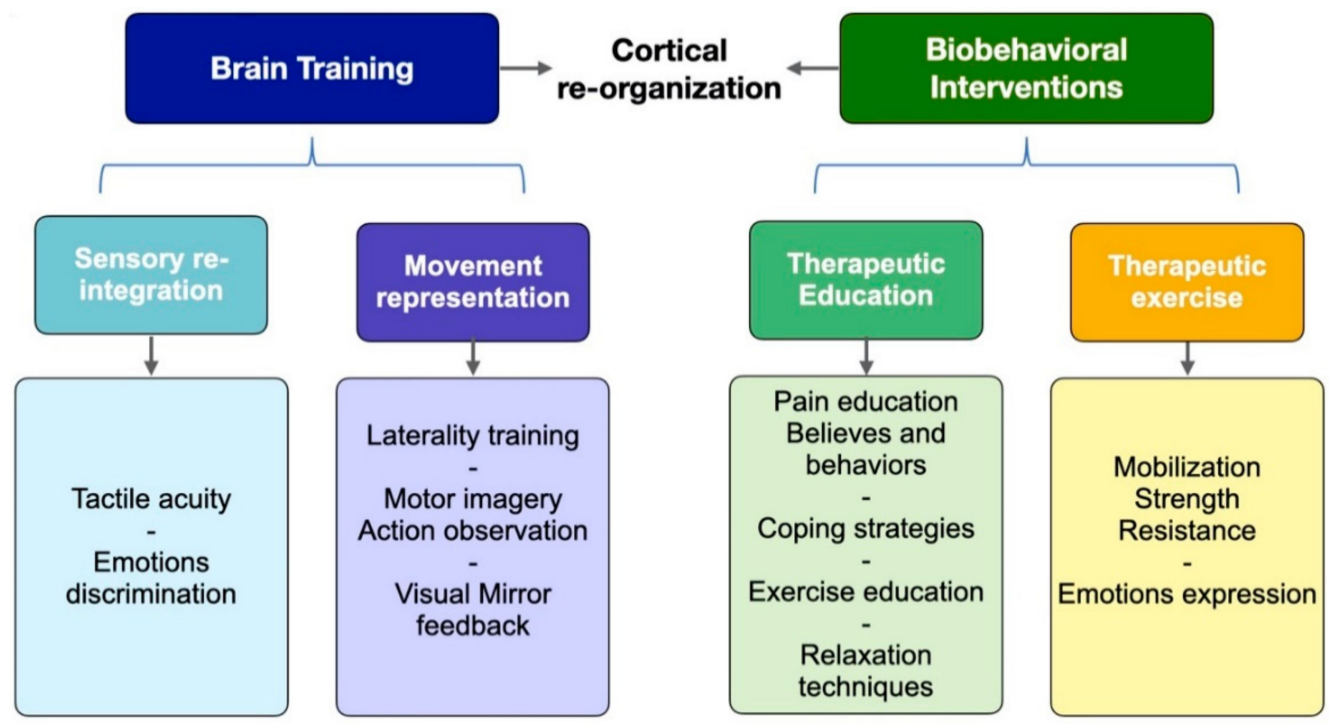

Scheme 2. Scheme of the intervention strategies aiming cortical reorganization. The treatment proposals are based on two main aspects: the brain training and biobehavioral interventions. All the strategies that are represented in the scheme will be focused to the sensorimotor recovery of the patient.

Patients with COFP that in the assessment demonstrate to present with a somatorepresentation dysfunction with face perceptive distortion and discriminative dysfunction for tactile stimuli or emotions recognizing (spatial and emotional distortion) will benefit from strategies directed to influence over brain reorganization, with specific techniques that will focus on bran training. These interventions may also influence over pain and over the motor function on the face or head.

A scheme of the protocol proposed can be found at Scheme 2. The intervention should start with the patient's therapeutic education and followed by the sensory retraining and the movement representation techniques. The tactile training can be performed for 2 min of combining techniques several times per day. The movement representations technique should start with the lateral discrimination training, motor imagery and/or action observation. Finally, the integration of the movement execution with the action observation or visual mirror feedback therapy can be performed when including the motor training. The emotions discrimination training optimally should be performed after the movement representation techniques, due to the patients will need to improve the cortical representations. In this way, if a main objective with the patient is improving emotions recognition, the emotions expression could be trained firstly with motor imagery and action observation followed by the real execution of the face expressions, and lastly the emotions recognition training.

Table 1 is an overview of a possible rehabilitation program where face training is integrated. When symptoms improve and there is reduction in pain, increased motor function and improved body image, the strategy may be progressed (made longer, with 
more variations and with the addition of new steps). If symptoms and function should worsen, reduce time, variations and start a step lower. If face mirroring is accepted by the patient, a combination of all strategies is recommended or integration with exercise within the patient's context or in combination with graded exposure. During a dominant unilateral face pain, be aware that dysynchiria (looking to the virtual part of the face in the mirror and experiencing pain or dysesthesia in the hidden affected face part) might be an observed phenomenon which may can cause a backlash with an increase in pain an or fear [176]. In some of the literature, it is observed that results during recognition tasks may be influenced by the state of the dysfunction (peripheral vs. central sensitizing), gender and age [177]. This will not influence the rehabilitation strategies suggested in Table 1 but may slow down the process of progression of rehabilitation.

Table 1. Overview of a possible face training focused on distortion of orofacial somatorepresentation.

\begin{tabular}{ccl}
\hline $\begin{array}{c}\text { Sequence of Training } \\
\text { (Task Levels) }\end{array}$ & \multicolumn{1}{c}{ Baseline } \\
\hline & $\bullet \quad \begin{array}{l}\text { Tactile sensitivity task } \\
\text { (location identification) }\end{array}$ \\
1. Tactile acuity training & $\bullet \quad \begin{array}{l}\text { Two-point discrimination } \\
\text { Enfacement training }\end{array}$ \\
& $\bullet \quad$ Training time: $1-2$ min each task \\
&
\end{tabular}

\section{Watching face activity left/right of picture}

- Start with 10 face pics, $>5 \mathrm{~s}$

- $\quad$ Task: Look at the picture and try to recognize if it is left right

\section{Progression}

When No Pain or Discomfort

- Tactile sensitivity task (textures discrimination)

- Directional sensitivity task

Training time: 1 to 2 min each task

Next, Step 2

Pain experience?

- $\quad$ Reduce pics and/or less fast.

No pain experience after progression; Next, Step 3

Pain experience?

- $\quad$ Start with 10-15 face pics

- $\quad$ Task: Quickly identify left/right side of the face and record number of correct answers and time
- +Left/right judgement (speed and accuracy) nearly equal?

- Progression: more pigs with(out) rotation $(90,180)$
3. Left/Right discrimination 3. Left/Right disc
training (implicit)

\section{Left/Right discrimination
training (explicit)}

- $\quad$ Start with 10-15 face pics

- Task: Quickly perform the movements in the face first the less symptomatic side
- $\quad$ Performing $50 \%$ left / right side and or more pics (>20)

5. Emotion recognition
(implicit)

5. Emoti
(implicit)

- Start with the 20 pics of the 3 best recognized emotions, $>5$

- Task: Look at the picture and try to RECOGNIZE which basic emotion you see

Note: dominant unilateral face pain: start with symmetrical emotions (e.g., happiness and surprise).
- Include $50 \%$ less recognized emotion

- Include more asymmetrical emotions pics (disgust > sadness and angry)

- $\quad$ More rotated pics
- Reduce pigs Step 1.

No pain experience after progression; Next, Step 4

Pain experience?

- $\quad$ Reduce symptom side to $25 \%$ or go back to Step 3

No pain experience after progression:

- Increase pics (>30) and faster; next, Step 5

\section{Pain experience?}

- Include more recognized emotions, symmetrical pics and or reduce time, less rotated pics

- $\quad$ Go back to Step 2

No pain experience after progression:

- Include more rotated, asymmetrical and not recognized pics; next, Step 6

Pain experience?

- $\quad$ Reduce speed and rotation

First

- $\quad$ Symmetrical pics

- $\quad$ Go back to Step 5

No pain experience after progression:

- $\quad$ include more speed, rotated, asymmetrical and not recognized pics; next, Step 7 
Table 1. Cont.

\begin{tabular}{|c|c|c|c|}
\hline $\begin{array}{l}\text { Sequence of Training } \\
\text { (Task Levels) }\end{array}$ & Baseline & $\begin{array}{c}\text { Progression } \\
\text { When No Pain or Discomfort }\end{array}$ & What If ...? \\
\hline $\begin{array}{l}\text { 7. Emotion expression } \\
\text { Movement (explicit) }\end{array}$ & $\begin{array}{l}\text { Start with the } 20 \text { pics of the } 3 \\
\text { best recognized emotions } \\
\text { Task: Look at the picture and } \\
\text { try to IMITATE the emotion } \\
\text { you see. } \\
\text { Note: Start with symmetrical emotions } \\
\text { (e.g., happiness and surprise) and } \\
\text { afterwards with asymmetrical, with } \\
\text { accent on the not symptomatic side. }\end{array}$ & $\begin{array}{ll}\text { - } & \text { Increase speed } \\
\text { - } & \text { Include } 50 \% \text { less recognized } \\
\text { emotion } & \text { Include more asymmetrical } \\
\text { emotions pics (disgust }> \\
\text { - } & \text { Madness and angry) } \\
\text { - } & \text { Alternation with left/right } \\
& \text { judgment pics. }\end{array}$ & $\begin{array}{l}\text { Pain experience? } \\
\text { - } \quad \begin{array}{l}\text { Reduce speed and L/R } \\
\text { decimation pics }\end{array} \\
\text { - } \quad \text { Reduce asymmetrical pics } \\
\text { - } \quad \text { Go back to Step } 6 \\
\text { No pain experience after progression: } \\
\text { - } \quad \text { Include more speed, rotated, } \\
\text { asymmetrical and not } \\
\text { recognized and left/right } \\
\text { discrimination pics; next, } \\
\text { Step } \\
\text { Note: Do not start with mirroring if } \\
\text { the pain and fear is increasing during } \\
\text { the tasks. }\end{array}$ \\
\hline 8. Face mirroring & $\begin{array}{l}\text { Patient looks in the mirror } \\
\text { where the less affected side is } \\
\text { projected on the most affected } \\
\text { side. } \\
\text { Task: Move less affected side } \\
\text { of the less painful face } \\
\text { movement (first left/right } \\
\text { judgement pics) } \\
\text { Note: Watch out for dysynchiria (see } \\
\text { text). }\end{array}$ & $\begin{array}{l}\text { Include the painful } \\
\text { movements with about 50\% } \\
\text { (first left/right judgement } \\
\text { pics). } \\
\text { Cover lower or upper part } \\
\text { of the face. }\end{array}$ & $\begin{array}{l}\text { Pain experience and or dysynchiria } \\
\text { - } \quad \text { Only looking in the mirror } \\
\text { without movement and } \\
\text { increase time } \\
\text { - } \quad \text { Go back to Step } 7 \text { or } 6 \\
\text { No pain experience after progression } \\
\text { - } \quad \text { Projection of the more } \\
\text { affected side on the less } \\
\text { affected side and start again } \\
\text { with the first task of Step } 8\end{array}$ \\
\hline 9. Combinations & $\begin{array}{l}\text { Randomization of task levels } 2-7 \text {. } \\
\text { Task: Start with maximum of } 3 \text { tasks } \\
\text { levels, } \\
\text { about } 3-5 \text { min }\end{array}$ & $\begin{array}{l}\text { - } \quad \text { Explore with more task } \\
\text { levels up till } 7 . \\
\text { Increase time serial (e.g.,: } 2 \\
\text { times, } 3 \text { min). }\end{array}$ & $\begin{array}{l}\text { Pain experience and or dysynchiria } \\
\text { - } \quad \text { Train the task levels } \\
\text { separately } \\
\text { - } \quad \text { which cause the complaints } \\
\text { - } \quad \text { Train the transitions of the } \\
\text { separate task levels } \\
\text { - Go back to Step } 7 \\
\text { No pain experience after progression } \\
\text { - } \quad \text { Go to Step } 8\end{array}$ \\
\hline
\end{tabular}

Include the following exercises to the previous:

lateral tongue strengthening,

Mouth opening with lingual guide,

10. Orofacial exercises lateral jaw movement, lateral jaw mobilization with lingual guide. 1 set/ 8 repetitions of each exercise tongue strengthening exercise,

lateral jaw movement strengthening, tongue protrusion strengthening, lip strength exercise.

1 set/10 repetitions holding $10 \mathrm{~s}$ each, and $10 \mathrm{~s}$ rest in between.
Pain experience?

- $\quad$ Reduce number of repetitions, increase rest time

No pain experience after progression Include a second set of all the exercises.

\section{Pain or fear experience?}

- Go back on the top of the list

- Cover upper /lower left/right side of the face

- $\quad$ Go back to Steps 8 and 7 behavioral

Methods facial activity (top 5 list).

Task: Start with the activity which causes less fear / pain with visual control with the mirror.
Progress from 4 to 1 of the list

\subsection{Tactile Acuity Training}

\subsubsection{Tactile Sensitivity Training}

Tactile stimuli applied in front of a mirror to compare the feeling in both sides. Tactile stimuli applied with different textures and eyes closed. The patients will have to identify the location and texture $[146,149]$. 


\subsubsection{Directional Sensitivity Training}

Application of a tactile stimuli with a small brush changing direction after each touch (eyes closed). The patient will have to identify the direction of the stimuli: superior, inferior, and to the right or to the left (out, in) $[151,178]$.

\subsubsection{Two-Point Discrimination Training}

Application of two points stimuli alternating one point and two-point stimuli with a distance large enough so the patient is able to discriminate. The patients will have to discriminate between "one or two" [146,149].

\subsubsection{Enfacement Training}

Visual-tactile illusion training: The patient's face will be touched with a cotton swab while he/she observes another face being touched (the therapist or a video recording) $[179,180]$.

\subsection{Movement Representation Techniques \\ 9.2.1. Left/Right Recognition}

The patient will be exposed to pictures with facial movements (non-emotional) performed with the eyes, lips, tongue and jaw. The patient will have to identify on which side of the face the movement is being performed. See also Figure 4 and Table 1 [50].

\subsubsection{Motor Imagery and/or Action Observation}

The face motor imagery (MI) and action observation (AO) can be performed separately or combined. In the first one, the patient will have to imagine face movements and in the second the patients will observe face movements. In the action observation, the patient will have to observe the action performed in a video recording of the facial movements. To perform the combined strategy $(\mathrm{MI}+\mathrm{AO})$, the patient will have to observe the recording of the action while imaging he/she is performing the same movement. The intervention protocol should be conformed of one or two series of 10 repetitions of at least six facial movements [175], such as tongue protrusion, right or left movements, jaw opening, right or left movements, one eye closing and lips movement to the right or to the left. A graded exposure to the volume of the training should be performed, increasing in number of repetitions and series of the exercises, and always assessing the fatigue and the beginning of the pain experience.

\subsubsection{Visual Mirror Feedback Therapy}

The integration of an exercise performed in front of a mirror should be performed with a focus on the motor aspect of the movements. The patients will have to perform the face movements in front of a mirror or with a special PC program (https:/ / www. myfacetraining.com, accessed on 15 June 2021) to obtain a feedback to be able to improve the motor execution (Figure 5). 


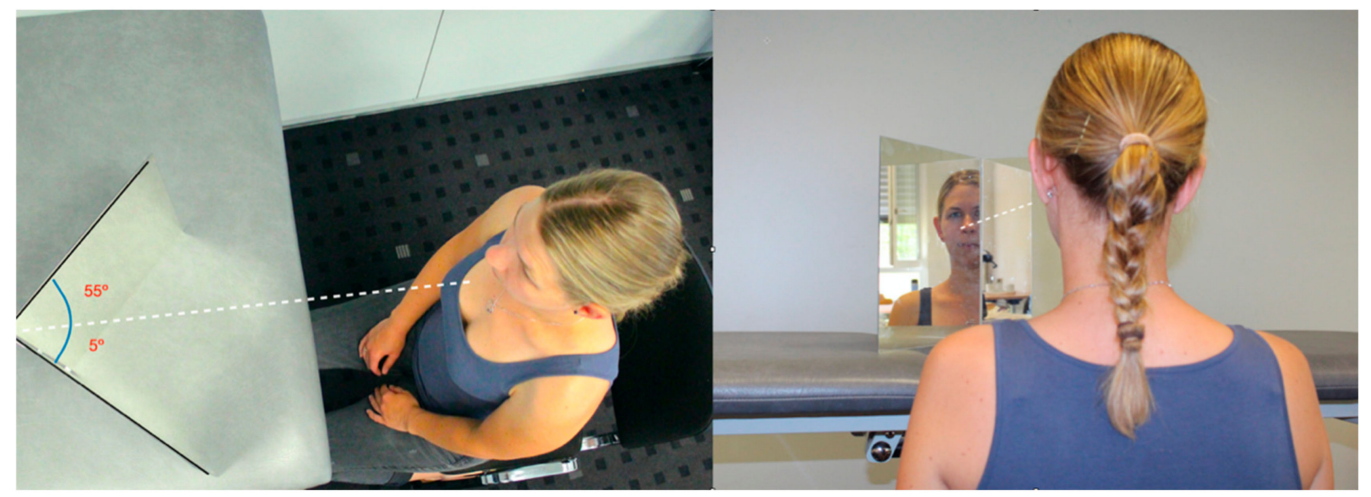

Figure 5. Visual mirror feedback by two mirrors of $30 \mathrm{~cm}$ by $30 \mathrm{~cm}$ with an angle of 100 degrees towards each other. The patient is facing the middle of the two mirrors whereby the right side of the face is projected on the left side when the right side is rotated for 55 degrees. For the left side, it is opposite.

\subsection{Emotions Representation}

Facial emotional gestures can be trained through movement representations techniques (MI, AO and MT) focusing in the emotional expression in addition to the motor execution. In this way emotional movements of facial expressions will be trained through the recognition and the mental and real practice of them [50].

\subsubsection{Emotions Recognition}

The patient will have to identify the facial emotion that is been presented in a picture [133].

\subsubsection{Facial Expression Training}

The same strategies already exposed for the movement representation intervention could be performed but using face emotional movements, starting from the imagery of the facial expression, following with the action observation and ending with the integration of the execution in front of a mirror or with a special PC program (see Figure 3).

\subsection{Face Motor Training through Movement Execution}

Training of the motor system achieves a cortical reorganization demonstrate by the reduction of pain and improvement of movement. When training facial movements neuroplasticity of the face PM cortex area is enhanced [181].

Physical training enhances mirror-system activation to action observation [182]. Therefore, at this point, action observation could be combined with the movement execution to enhance the benefits of the motor training. The inclusion of the mirror feedback also will help to improve the motor execution.

The orofacial exercise protocol to use is based in several face and tongue movements, combining mobility and strengthening exercises. These exercises can be used in the movement representation intervention, as has been previously published [175] (Figure 6).

- Mouth opening exercise with lingual guide. Mouth opening movement with the tongue towards the palate. One set/eight repetitions.

- Lateral jaw movement. Lateral jaw movement with a tongue depressor between the incisors to guide the movement. One set/eight repetitions each side.

- Lateral tongue strengthening. Extrabuccal tongue lateral isometric force towards a tongue depressor placed (held vertically). One set/10 repetitions holding $10 \mathrm{~s}$ each. Ten-second rest in between.

- Lateral jaw mobilization exercise with lingual guide. Jaw lateral movement with a lateral protrusion of the tongue to guide the movement to the same side. One set/eight repetitions 
- Tongue strengthening exercise. With an anterior protrusion of the tongue a depressor placed on the tongue, an isometric force upwards and against the depressor. One set/10 repetitions holding $10 \mathrm{~s}$ each. Ten-second rest in between.

- Lateral jaw movement strengthening. Jaw lateral movement with a slight external resistance to permit resisted movement. One set/eight repetitions each side.

- Tongue protrusion strengthening. Isometric force with a tongue protrusion towards a tongue depressor (held vertically). One set/10 repetitions holding $10 \mathrm{~s}$ each. Tensecond rest in between.

- Lip strength exercise. Isometric exercise holding the lips in a closed and thigh position with a tongue depressor between them. One set/10 repetitions holding $10 \mathrm{~s}$ each. Ten-second rest in between.
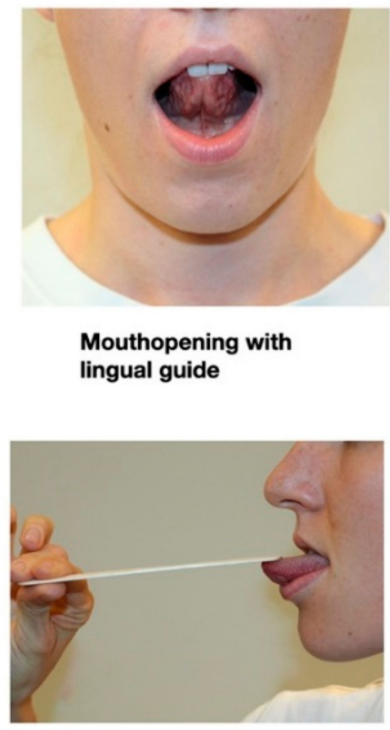

Tongue strengthening exercise with tongue depressor

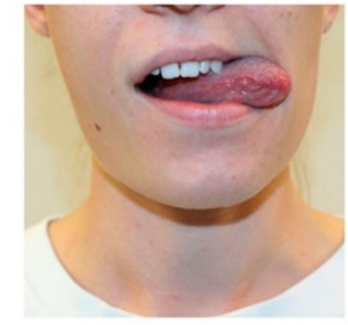

Lateral mandibula exercise with lingual guide

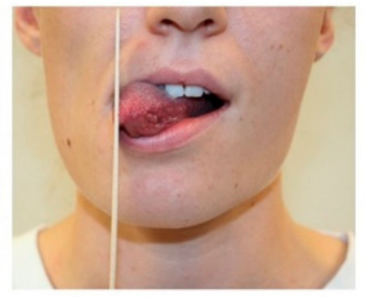

Lateral tongue strengthening with tongue depressor

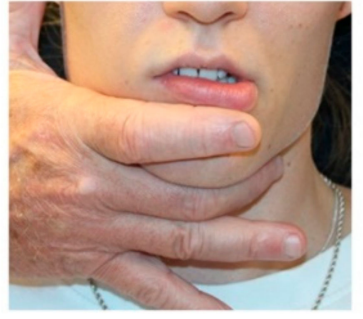

Lateral mandibula exercise movement strengthening

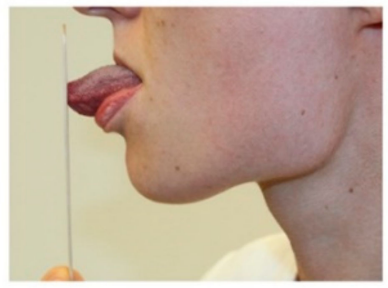

Tongue protrusion strengthening with tongue depressor

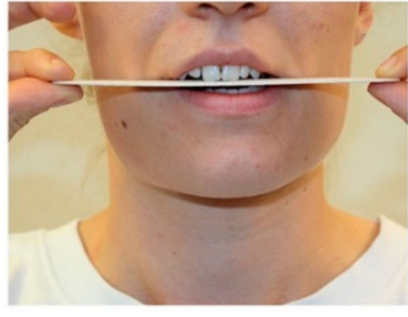

Lateral mandibula movement with tongue depressor

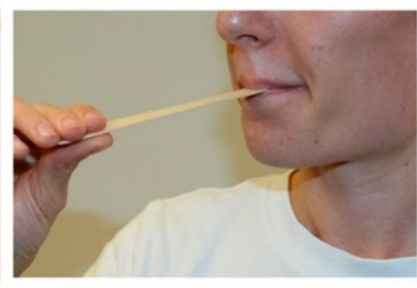

Lip strengthening with tongue depressor

Figure 6. Face motor-training exercises.

\subsection{Masticatory Training}

When an altered masticatory pattern is identified as unilateral mastication, the rehabilitation of the mastication at the contralateral side should be performed. The same graded exposure protocol used for movement representation can be used at this point, but it would be especially important to include action observation, such as mirror feedback therapy and tactile stimuli with eyes open and closed (as a proprioceptive feedback) when training the movement execution.

Mastication can be trained with gum; the patient will have to chew the gum at the non-habitual chewing side. The mastication will be performed at a $60 \mathrm{bpm}$ assured by a metronome. Initially in front of a mirror, the mastication pattern will be trained assuring the lateral movement of the jaw is happening; if not, a tactile stimulus on the lateral side of the mandibular body will help to direct the movement towards the tactile stimuli. If the patients have problems performing the lateral movement during mastication, the observation of the masticatory correct pattern focusing in the affected side will help to improve the cortical representation of the movement (Figure 7). The training will start with a duration of minutes, until the pattern of the movement cannot be performed correctly due to fatigue, and increased progressively until no more than $6 \mathrm{~min}$ of mastication, alternating sides after each minute [183]. 


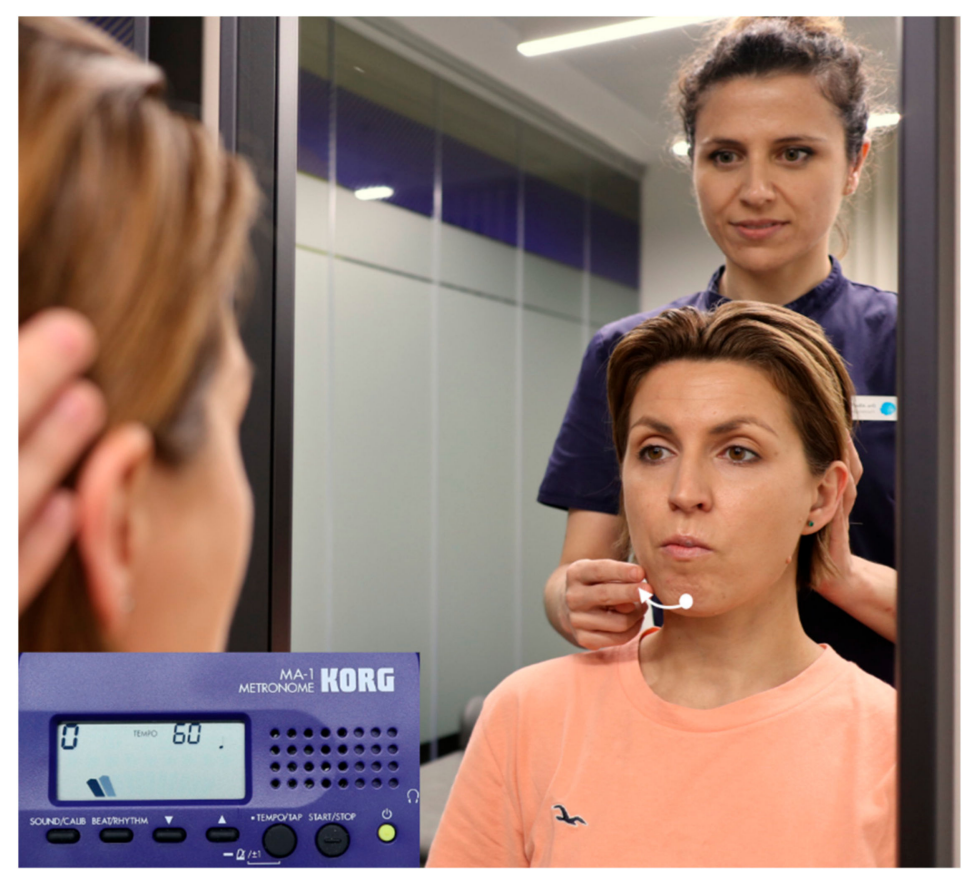

Figure 7. Masticatory training. Mandibular movements to the non-habitual masticatory side should be trained during mastication at a rhythm of $60 \mathrm{bpm}$ controlled by a metronome. Perform in front of a mirror to have a visual feedback for both the patient and physiotherapist. Tactile stimuli, to indicate the side towards where the mandibular movement should be performed; may be applied if the patient has difficulties for performing the lateral movement.

\subsection{Therapeutic Patient Education}

In traditional physical-therapy educational models, patients are often educated via a biomedical model of their underlying pain experience, which is based on anatomy, pathoanatomy and their pain $[184,185]$. By contrast, therapeutic patient education focuses on a biobehavioral approach, including neuroeducation pain education and behavioral strategies. One of the aims of the PTE is teaching patients more about the underlying neurobiological and neurophysiological processes $[186,187]$. Simplified systematical teaching of pain mechanisms, such as peripheral, central sensitization, spread of pain without damage, the influence of cognitive-affective factors and treat experience, the pain-neuromatrix and changes in body perceptions, with images and metaphors has proven to have a satisfactory outcome in different (chronic) musculoskeletal pain syndromes [188].

The other aim of the PTE is teaching active coping strategies and other strategies to help manage fear-avoidance beliefs and modulate pain [189]. These other strategies are distraction strategies, changing behaviors and misconceptions about pain and body perception, teaching on the benefits of therapeutic exercise and general physical activity, relaxation techniques and correction of inappropriate behaviors, such as parafunctions of the TMJ. The biobehavioral intervention has shown positive effects for reducing chronic pain [189-191].

The authors believe that a multimodal approach including a biobehavioral intervention through therapeutic patient education in COFP and headaches in combination with manual therapy, auditory, motor and tactile acuity exercises and movement representation training may help with restoring the individual face perception of the patient, as well as reducing pain and improving motor function.

\section{Reflection and Conclusions}

- In this narrative review, an overview was given of the actual (scarce) external evidence on orofacial somatorepresentation distortion supporting clinical assessment and management. 
- The authors have tried to integrate the scarce evidence found regarding the mentioned condition with the theoretical bases of the neuroscience behind the process, together with their clinical experience, in a treatment proposal of therapeutic interventions that might help improve pain, face perceptions and function and therefore quality of life.

- This overview article may challenge clinical research regenerating innovative research questions and its implementation.

- Suggestions which may be implemented in clinical research for Orofacial Somatorepresentation Distortion (OFSD) are as follows:

$\bigcirc \quad$ Qualities of OFSD related with DC/TMD classification (Axis I and II) and IASP for example primary and secondary chronic pain, peripheral sensitized and central sensitization dominance conditions.

Clinical subclassifications of OFSD.

OFSD qualities during unilateral versus bilateral facial symptoms.

The mutual degree of change of the acuity (visual, proprioceptive, acoustic and tactile) during the proposed rehabilitation strategy within different syndromes and diagnoses.

Author Contributions: Conceptualization, H.v.P. and A.P.-A.; writing—original draft preparation, H.v.P. and A.P.-A.; writing-review and editing, H.v.P. and A.P.-A. All authors have read and agreed to the published version of the manuscript.

Funding: This research received no external funding.

Institutional Review Board Statement: Not applicable.

Informed Consent Statement: Not applicable.

Data Availability Statement: Not applicable.

Acknowledgments: The authors would like to thank the Institute of Neuroscience and Science of The Movement (INCIMOV) for its service in adapting this manuscript.

Conflicts of Interest: The authors declare no conflict of interest.

\section{References}

1. LeResche, L. Epidemiology of Temporomandibular Disorders: Implications for the Investigation of Etiologic Factors. Critical reviews in oral biology and medicine: An official publication of the American Association of Oral Biologists. Crit. Rev. Oral Biol. Med. 1997, 8, 291-305. [CrossRef] [PubMed]

2. Lipton, J.; Ship, J.; Larach-Robinson, D. Estimated Prevalence and Distribution of Reported Orofacial Pain in the United States. J. Am. Dent. Assoc. 1993, 124, 115-121. [CrossRef]

3. Breivik, H.; Collett, B.; Ventafridda, V.; Cohen, R.; Gallacher, D. Survey of chronic pain in Europe: Prevalence, impact on daily life, and treatment. Eur. J. Pain 2006, 10, 287. [CrossRef]

4. Von Korff, M.; Dworkin, S.F.; Le Resche, L.; Kruger, A. An epidemiologic comparison of pain complaints. Pain 1988, 32, 173-183. [CrossRef]

5. Haggman-Henrikson, B.; Liv, P.; Ilgunas, A.; Visscher, C.M.; Lobbezoo, F.; Durham, J.; Lövgren, A. Increasing gender differences in the prevalence and chronification of orofacial pain in the population. Pain 2020, 161, 1768-1775. [CrossRef]

6. Headache Classification Committee of the International Headache Society (IHS) The International Classification of Headache Disorders, 3rd edition. Cephalalgia 2018, 38, 1-211. [CrossRef]

7. International Classification of Orofacial Pain, 1st edition (ICOP). Cephalalgia 2020, 40, 129-221. [CrossRef]

8. Ziegeler, C.; May, A. The ICHD definition of 'facial pain' should be revised. Cephalalgia 2020, 40, 1398-1399. [CrossRef]

9. Ananthan, S.; Benoliel, R. Chronic orofacial pain. J. Neural Transm. 2020, 127, 575-588. [CrossRef] [PubMed]

10. Schiffman, E.; Ohrbach, R.; Truelove, E.; Look, J.; Anderson, G.; Goulet, J.-P.; List, T.; Svensson, P.; Gonzalez, Y.; Lobbezoo, F.; et al. Diagnostic Criteria for Temporomandibular Disorders (DC/TMD) for Clinical and Research Applications: Recommendations of the International RDC/TMD Consortium Network * and Orofacial Pain Special Interest Group t. J. Oral Facial Pain Headache 2014, 28, 6-27. [CrossRef] [PubMed]

11. Dando, W.E.; Branch, M.A.; Maye, J.P. Headache Disability in Orofacial Pain Patients. Headache J. Head Face Pain 2006, 46, 322-326. [CrossRef]

12. Storm, C.; Wänman, A. Temporomandibular disorders, headaches, and cervical pain among females in a Sami population. Acta Odontol. Scand. 2006, 64, 319-325. [CrossRef] [PubMed] 
13. Tal, M.; Villanueva, L.; Devor, M. Anatomy and neurophysiology of orofacial pain. In Orofacial Pain E Headache; Sharav, Y., Benoliel, R., Eds.; Quintessence Publishing: Chicago, IL, USA, 2015; pp. 31-77.

14. Shinoda, M.; Kubo, A.; Hayashi, Y.; Iwata, K. Peripheral and Central Mechanisms of Persistent Orofacial Pain. Front. Neurosci. 2019, 13, 1227. [CrossRef]

15. Craddock, C.; Jbabdi, S.; Yan, C.-G.; Vogelstein, J.; Castellanos, F.; Di Martino, A.; Kelly, C.; Heberlein, K.; Colcombe, S.; Milham, M.P. Imaging human connectomes at the macroscale. Nat. Methods 2013, 10, 524-539. [CrossRef]

16. Shueb, S.; Nixdorf, D.; John, M.; Alonso, B.F.; Durham, J. What is the impact of acute and chronic orofacial pain on quality of life? J. Dent. 2015, 43, 1203-1210. [CrossRef]

17. Slade, G.; Ohrbach, R.; Greenspan, J.; Fillingim, R.; Bair, E.; Sanders, A.; Dubner, R.; Diatchenko, L.; Meloto, C.; Smith, S.; et al. Painful Temporomandibular Disorder. J. Dent. Res. 2016, 95, 1084-1092. [CrossRef]

18. Lei, J.; Liu, M.-Q.; Yap, A.U.J.; Fu, K.-Y. Sleep Disturbance and Psychologic Distress: Prevalence and Risk Indicators for Temporomandibular Disorders in a Chinese Population. J. Oral Facial Pain Headache 2015, 29, 24-30. [CrossRef]

19. Ziegeler, C.; Schulte, L.H.; May, A. Altered trigeminal pain processing on brainstem level in persistent idiopathic facial pain. Pain 2021, 162, 1374-1378. [CrossRef]

20. Harper, D.; Schrepf, A.; Clauw, D. Pain Mechanisms and Centralized Pain in Temporomandibular Disorders. J. Dent. Res. 2016, 95, 1102-1108. [CrossRef]

21. Lin, C.-S. Brain Signature of Chronic Orofacial Pain: A Systematic Review and Meta-Analysis on Neuroimaging Research of Trigeminal Neuropathic Pain and Temporomandibular Joint Disorders. PLoS ONE 2014, 9, e94300. [CrossRef]

22. La Touche, R.; Paris-Alemany, A.; Hidalgo-Pérez, A.; López-De-Uralde-Villanueva, I.; Angulo-Diaz-Parreño, S.; Muñoz-García, D. Evidence for Central Sensitization in Patients with Temporomandibular Disorders: A Systematic Review and Meta-analysis of Observational Studies. Pain Pract. 2018, 18, 388-409. [CrossRef] [PubMed]

23. Garrigós-Pedrón, M.; La Touche, R.; Desentre, P.N.; Gracia-Naya, M.; Segura-Ortí, E. Widespread mechanical pain hypersensitivity in patients with chronic migraine and temporomandibular disorders: Relationship and correlation between psychological and sensorimotor variables. Acta Odontol. Scand. 2019, 77, 224-231. [CrossRef] [PubMed]

24. Nasri-Heir, C.; Khan, J.; Benoliel, R.; Feng, C.; Yarnitsky, D.; Kuo, F.; Hirschberg, C.; Hartwell, G.; Huang, C.-Y.; Heir, G.; et al. Altered pain modulation in patients with persistent postendodontic pain. Pain 2015, 156, 2032-2041. [CrossRef] [PubMed]

25. Gil-Martinez, A.; Paris-Alemany, A.; López-De-Uralde-Villanueva, I.; La Touche, R. Management of pain in patients with temporomandibular disorder (TMD): Challenges and solutions. J. Pain Res. 2018, 11, 571-587. [CrossRef]

26. Ettlin, D.A.; Napimoga, M.H.; e Cruz, M.M.; Clemente-Napimoga, J.T. Orofacial musculoskeletal pain: An evidence-based bio-psycho-social matrix model. Neurosci. Biobehav. Rev. 2021, 128, 12-20. [CrossRef]

27. Valmunen, T.; Pertovaara, A.; Taiminen, T.; Virtanen, A.; Parkkola, R.; Jääskeläinen, S.K. Modulation of facial sensitivity by navigated rTMS in healthy subjects. Pain 2009, 142, 149-158. [CrossRef]

28. Sterling, M.; Jull, G.; Wright, A. The effect of musculoskeletal pain on motor activity and control. J. Pain 2001, 2, 135-145. [CrossRef] [PubMed]

29. Vallence, A.-M.; Smith, A.; Tabor, A.; Rolan, P.E.; Ridding, M.C. Chronic tension-type headache is associated with impaired motor learning. Cephalalgia 2013, 33, 1048-1054. [CrossRef]

30. Weissman-Fogel, I.; Moayedi, M.; Tenenbaum, H.C.; Goldberg, M.B.; Freeman, B.V.; Davis, K.D. Abnormal cortical activity in patients with temporomandibular disorder evoked by cognitive and emotional tasks. Pain 2011, 152, 384-396. [CrossRef]

31. Salomons, T.V.; Moayedi, M.; Weissman-Fogel, I.; Goldberg, M.B.; Freeman, B.V.; Tenenbaum, H.C.; Davis, K.D. Perceived helplessness is associated with individual differences in the central motor output system. Eur. J. Neurosci. 2012, 35, $1481-1487$. [CrossRef]

32. Tucker, K.; Larsson, A.-K.; Oknelid, S.; Hodges, P. Similar alteration of motor unit recruitment strategies during the anticipation and experience of pain. Pain 2012, 153, 636-643. [CrossRef]

33. Moseley, G.L.; Flor, H. Targeting Cortical Representations in the Treatment of Chronic Pain. Neurorehabilit. Neural Repair 2012, 26, 646-652. [CrossRef] [PubMed]

34. La Touche, R.; Cuenca-Martínez, F.; Suso-Martí, L.; García-Vicente, A.; Navarro-Morales, B.; Paris-Alemany, A. Tactile trigeminal region acuity in temporomandibular disorders: A reliability and cross-sectional study. J. Oral Rehabil. 2019, 47, 9-18. [CrossRef] [PubMed]

35. Michelotti, A.; Farella, M.; Stellato, A.; Martina, R.; De Laat, A. Tactile and pain thresholds in patients with myofascial pain of the jaw muscles: A case-control study. J. Orofac. Pain 2008, 22, 139-145. [CrossRef] [PubMed]

36. Uritani, D.; Nishida, T.; Sakaguchi, N.; Kawakami, T.; Jones, L.; Kirita, T. Difference in Response to a Motor Imagery Task: A Comparison between Individuals with and without Painful Temporomandibular Disorders. Pain Res. Manag. 2018, 2018, 1-8. [CrossRef] [PubMed]

37. Dagsdóttir, L.K.; Skyt, I.; Vase, L.; Baad-Hansen, L.; Castrillon, E.; Svensson, P. Reports of perceptual distortion of the face are common in patients with different types of chronic oro-facial pain. J. Oral Rehabil. 2016, 43, 409-416. [CrossRef] [PubMed]

38. Von Piekartz, H.; Wallwork, S.B.; Mohr, G.; Butler, D.S.; Moseley, L. People with chronic facial pain perform worse than controls at a facial emotion recognition task, but it is not all about the emotion. J. Oral Rehabil. 2014, 42, 243-250. [CrossRef]

39. Chaves, A.C.S.; Reis, F.J.J.; Bandeira, P.M.; Fernandes, O.; Sanchez, T.A. Autonomic dysregulation and impairments in the recognition of facial emotional expressions in patients with chronic musculoskeletal pain. Scand. J. Pain 2021. [CrossRef] 
40. Harvie, D.; Edmond-Hank, G.; Smith, A.D. Tactile acuity is reduced in people with chronic neck pain. Musculoskelet. Sci. Pract. 2018, 33, 61-66. [CrossRef] [PubMed]

41. Bustan, S.; González-Roldán, A.M.; Schommer, C.; Kamping, S.; Löffler, M.; Brunner, M.; Flor, H.; Anton, F. Psychological, cognitive factors and contextual influences in pain and pain-related suffering as revealed by a combined qualitative and quantitative assessment approach. PLoS ONE 2018, 13, e0199814. [CrossRef]

42. Juottonen, K.; Gockel, M.; Silén, T.; Hurri, H.; Hari, R.; Forss, N. Altered central sensorimotor processing in patients with complex regional pain syndrome. Pain 2002, 98, 315-323. [CrossRef]

43. Younger, J.W.; Shen, Y.F.; Goddard, G.; Mackey, S. Chronic myofascial temporomandibular pain is associated with neural abnormalities in the trigeminal and limbic systems. Pain 2010, 149, 222-228. [CrossRef]

44. Stamper, G.C.; Johnson, T.A. Auditory Function in Normal-Hearing, Noise-Exposed Human Ears. Ear Hear. 2015, 36, 172-184. [CrossRef]

45. Muhr, P.; Rosenhall, U. Self-assessed auditory symptoms, noise exposure, and measured auditory function among healthy young Swedish men. Int. J. Audiol. 2010, 49, 317-325. [CrossRef] [PubMed]

46. Suhnan, A.P.; Finch, P.M.; Drummond, P.D. Hyperacusis in chronic pain: Neural interactions between the auditory and nociceptive systems. Int. J. Audiol. 2017, 56, 801-809. [CrossRef] [PubMed]

47. Moseley, L.; Jones, M. Chronic Facial Pain in a 24-Year-Old University Student. In Clinical Reasoning in Musculoskeletal Practice; Elsevier BV: Edinburgh, Scotland, 2019; pp. 150-163.

48. Luedtke, K.; Edlhaimb, J. Laterality judgements in patients with frequent episodic migraine. Musculoskelet. Sci. Pract. 2021, 51, 102316. [CrossRef] [PubMed]

49. Diaz-Saez, M.; Gil-Martínez, A.; González, I.I.; Lee, J.K.; De-Vera, J.D.-C.P.; Carretero, J.C.; Beltran-Alacreu, H. A novel mobile application to determine mandibular and tongue laterality discrimination in women with chronic temporomandibular disorder. Med. Oral Patol. Oral Cir. Bucal 2020, 25, e775-e783. [CrossRef]

50. Von Piekartz, H.; Mohr, G. Reduction of head and face pain by challenging lateralization and basic emotions: A proposal for future assessment and rehabilitation strategies. J. Man. Manip. Ther. 2014, 22, 24-35. [CrossRef]

51. Jeannerod, M. Mental imagery in the motor context. Neuropsychologia 1995, 33, 1419-1432. [CrossRef]

52. Dickstein, R.; Deutsch, J.E. Motor Imagery in Physical Therapist Practice. Phys. Ther. 2007, 87, 942-953. [CrossRef]

53. Lotze, M.; Halsband, U. Motor imagery. J. Physiol. 2006, 99, 386-395. [CrossRef]

54. Vannuscorps, G.; Pillon, A.; Andres, M. Effect of biomechanical constraints in the hand laterality judgment task: Where does it come from? Front. Hum. Neurosci. 2012, 6, 299. [CrossRef] [PubMed]

55. Bellan, V.; Wallwork, S.B.; Gallace, A.; Spence, C.; Moseley, G.L. Integrating Self-Localization, Proprioception, Pain, and Performance. J. Danc. Med. Sci. 2017, 21, 24-35. [CrossRef]

56. Osuagwu, B.A.; Vuckovic, A. Similarities between explicit and implicit motor imagery in mental rotation of hands: An EEG study. Neuropsychologia 2014, 65, 197-210. [CrossRef]

57. Hanakawa, T.; Immisch, I.; Toma, K.; Dimyan, M.; Van Gelderen, P.; Hallett, M. Functional Properties of Brain Areas Associated with Motor Execution and Imagery. J. Neurophysiol. 2003, 89, 989-1002. [CrossRef]

58. Avivi-Arber, L.; Martin, R.; Lee, J.-C.; Sessle, B.J. Face sensorimotor cortex and its neuroplasticity related to orofacial sensorimotor functions. Arch. Oral Biol. 2011, 56, 1440-1465. [CrossRef]

59. Sessle, B.J.; Yao, D.; Nishiura, H.; Yoshino, K.; Lee, J.-C.; Martin, R.E.; Murray, G.M. Properties and plasticity of the primate somatosensory and motor cortex related to orofacial sensorimotor function. Clin. Exp. Pharmacol. Physiol. 2005, 32, 109-114. [CrossRef] [PubMed]

60. Moreau, D. Unreflective actions? complex motor skill acquisition to enhance spatial cognition. Phenomenol. Cogn. Sci. 2015, 14, 349-359. [CrossRef]

61. Moseley, G.L.; Gallace, A.; Spence, C. Bodily illusions in health and disease: Physiological and clinical perspectives and the concept of a cortical 'body matrix'. Neurosci. Biobehav. Rev. 2012, 36, 34-46. [CrossRef]

62. Sato, S.; Ohta, M.; Sawatari, M.; Kawamura, H.; Motegi, K. Occlusal contact area, occlusal pressure, bite force, and masticatory efficiency in patients with anterior disc displacement of the temporomandibular joint. J. Oral Rehabil. 1999, 26, 906-911. [CrossRef] [PubMed]

63. Sato, S.; Nasu, F.; Motegi, K. Natural course of nonreducing disc displacement of the temporomandibular joint: Changes in chewing movement and masticatory efficiency. J. Oral Maxillofac. Surg. 2002, 60, 867-872. [CrossRef] [PubMed]

64. Weber, P.; Corrêa, E.C.R.; Bolzan, G.D.P.; Ferreira, F.D.S.; Soares, J.C.; Da Silva, A.M.T. Mastigação e deglutição em mulheres jovens com desordem temporomandibular. CoDAS 2013, 25, 375-380. [CrossRef] [PubMed]

65. Coelho-Ferraz, M.J.P.; Berzin, F.; Amorim, C.F.; Romano, F.L.; Queluz, D.D.P. Electromyographic and cephalometric correlation with the predominant masticatory movement. Stomatologija 2010, 12, 51-55. [PubMed]

66. Santana-Mora, U.; López-Cedrún, J.; Mora, M.J.; Otero, X.L.; Santana-Penin, U. Temporomandibular Disorders: The Habitual Chewing Side Syndrome. PLoS ONE 2013, 8, e59980. [CrossRef] [PubMed]

67. Padmaja, B.; Neeharika, S.; Bindu, G.H.; Babu, N.S.; Madhulika, S. Predilection of Chewing Side Preferences and Clinical Assessment of Its Impact on Temporomandibular Joint. J. Dent. Allied Sci. 2018, 7, 65. [CrossRef]

68. Wiesinger, B.; Haggman-Henrikson, B.; Hellström, F.; Wänman, A. Experimental masseter muscle pain alters jaw-neck motor strategy. Eur. J. Pain 2012, 17, 995-1004. [CrossRef] 
69. Giurgola, S.; Pisoni, A.; Maravita, A.; Vallar, G.; Bolognini, N. Somatosensory cortical representation of the body size. Hum. Brain Mapp. 2019, 40, 3534-3547. [CrossRef]

70. Mora, L.; Cowie, D.; Banissy, M.J.; Cocchini, G. My true face: Unmasking one's own face representation. Acta Psychol. 2018, 191, 63-68. [CrossRef]

71. Skyt, I.; Dagsdóttir, L.; Vase, L.; Baad-Hansen, L.; Castrillon, E.; Roepstorff, A.; Jensen, T.S.; Svensson, P. Painful Stimulation and Transient Blocking of Nerve Transduction Due to Local Anesthesia Evoke Perceptual Distortions of the Face in Healthy Volunteers. J. Pain 2015, 16, 335-345. [CrossRef]

72. Costa, Y.; Castrillon, E.; Bonjardim, L.; Conti, P.R.; Baad-Hansen, L.; Svensson, P. Effects of Experimental Pain and Lidocaine on Mechanical Somatosensory Profile and Face Perception. J. Oral Facial Pain Headache 2017, 31, 115-123. [CrossRef]

73. Moseley, L.G. I can't find it! Distorted body image and tactile dysfunction in patients with chronic back pain. Pain 2008, 140, 239-243. [CrossRef]

74. Lewis, J.S.; Kersten, P.; McCabe, C.; McPherson, K.; Blake, D.R. Body perception disturbance: A contribution to pain in complex regional pain syndrome (CRPS). Pain 2007, 133, 111-119. [CrossRef]

75. Flor, H.; Braun, C.; Elbert, T.; Birbaumer, N. Extensive reorganization of primary somatosensory cortex in chronic back pain patients. Neurosci. Lett. 1997, 224, 5-8. [CrossRef]

76. Ekman, P. Emotions revealed. BMJ 2004, 328, 0405184. [CrossRef]

77. Haas, J.; Eichhammer, P.; Traue, H.C.; Hoffmann, H.; Behr, M.; Crönlein, T.; Pieh, C.; Busch, V. Alexithymic and somatisation scores in patients with temporomandibular pain disorder correlate with deficits in facial emotion recognition. J. Oral Rehabil. 2013, 40, 81-90. [CrossRef]

78. Von Piekartz, H.; Mohr, G.; Traue, H.C. Recognition of Emotional Facial Expressions and Alexithymia in Patients with Chronic Facial Pain. Ann. Psychiatry Ment. Health 2018, 6, 1134.

79. Keysers, C.; Gazzola, V. Expanding the mirror: Vicarious activity for actions, emotions, and sensations. Curr. Opin. Neurobiol. 2009, 19, 666-671. [CrossRef] [PubMed]

80. Van Heukelum, S.; Mars, R.; Guthrie, M.; Buitelaar, J.K.; Beckmann, C.F.; Tiesinga, P.H.; Vogt, B.A.; Glennon, J.; Havenith, M.N. Where is Cingulate Cortex? A Cross-Species View. Trends Neurosci. 2020, 43, 285-299. [CrossRef]

81. Paradiso, E.; Gazzola, V.; Keysers, C. Neural mechanisms necessary for empathy-related phenomena across species. Curr. Opin. Neurobiol. 2021, 68, 107-115. [CrossRef] [PubMed]

82. Meffert, H.; Gazzola, V.; Boer, J.A.D.; Bartels, A.A.J.; Keysers, C. Reduced spontaneous but relatively normal deliberate vicarious representations in psychopathy. Brain 2013, 136, 2550-2562. [CrossRef] [PubMed]

83. Brown, T.; Kucharska, K.; Wilkos, E.; Sławinska, K. Social cognitive and neurocognitive deficits in inpatients with unilateral thalamic lesions-Pilot study. Neuropsychiatr. Dis. Treat. 2015, 11, 1031-1038. [CrossRef] [PubMed]

84. Shamay-Tsoory, S.G.; Aharon-Peretz, J.; Perry, D. Two systems for empathy: A double dissociation between emotional and cognitive empathy in inferior frontal gyrus versus ventromedial prefrontal lesions. Brain 2009, 132, 617-627. [CrossRef]

85. Perry, A.; Saunders, S.N.; Stiso, J.; Dewar, C.; Lubell, J.; Meling, T.R.; Solbakk, A.-K.; Endestad, T.; Knight, R.T. Effects of prefrontal cortex damage on emotion understanding: EEG and behavioural evidence. Brain 2017, 140, 1086-1099. [CrossRef]

86. Vaidya, A.R.; Fellows, L.K. Ventromedial frontal lobe damage affects interpretation, not exploration, of emotional facial expressions. Cortex 2019, 113, 312-328. [CrossRef]

87. Willis, M.L.; Palermo, R.; McGrillen, K.; Miller, L. The nature of facial expression recognition deficits following orbitofrontal cortex damage. Neuropsychologia 2014, 28, 613-623. [CrossRef] [PubMed]

88. Godin, B.R.; Oishi, K.; Oishi, K.; Davis, C.; Gomez, Y.; Trupe, L.A.; Kim, E.H.; Hillis, A.E.; Tippett, D.C. Impaired Recognition of Emotional Faces after Stroke Involving Right Amygdala or Insula. Semin. Speech Lang. 2018, 39, 87-100. [CrossRef]

89. Motomura, K.; Terasawa, Y.; Natsume, A.; Iijima, K.; Chalise, L.; Sugiura, J.; Yamamoto, H.; Koyama, K.; Wakabayashi, T.; Umeda, S. Anterior insular cortex stimulation and its effects on emotion recognition. Brain Struct. Funct. 2019, 224, 2167-2181. [CrossRef]

90. Boucher, O.; Rouleau, I.; Lassonde, M.; Lepore, F.; Bouthillier, A.; Nguyen, D.K. Social information processing following resection of the insular cortex. Neuropsychologia 2015, 71, 1-10. [CrossRef] [PubMed]

91. Adolphs, R. Neural systems for recognizing emotion. Curr. Opin. Neurobiol. 2002, 12, 169-177. [CrossRef]

92. Neal, D.T.; Chartrand, T.L. Embodied Emotion Perception. Soc. Psychol. Pers. Sci. 2011, 2, 673-678. [CrossRef]

93. Sato, W.; Fujimura, T.; Kochiyama, T.; Suzuki, N. Relationships among Facial Mimicry, Emotional Experience, and Emotion Recognition. PLoS ONE 2013, 8, e57889. [CrossRef]

94. Price, T.F.; Harmon-Jones, E. Embodied emotion: The influence of manipulated facial and bodily states on emotive responses. Wiley Interdiscip. Rev. Cogn. Sci. 2015, 6, 461-473. [CrossRef]

95. Kircher, T.; Pohl, A.; Krach, S.; Thimm, M.; Schulte-Rüther, M.; Anders, S.; Mathiak, K. Affect-specific activation of shared networks for perception and execution of facial expressions. Soc. Cogn. Affect. Neurosci. 2013, 8, 370-377. [CrossRef] [PubMed]

96. Kajal, D.S.; Fioravanti, C.; Elshahabi, A.; Ruiz, S.; Sitaram, R.; Braun, C. Involvement of top-down networks in the perception of facial emotions: A magnetoencephalographic investigation. NeuroImage 2020, 222, 117075. [CrossRef] [PubMed]

97. Zhen, Z.; Fang, H.; Liu, J. The Hierarchical Brain Network for Face Recognition. PLoS ONE 2013, 8, e59886. [CrossRef] [PubMed]

98. Kraaijenvanger, E.J.; Hofman, D.; Bos, P.A. A neuroendocrine account of facial mimicry and its dynamic modulation. Neurosci. Biobehav. Rev. 2017, 77, 98-106. [CrossRef]

99. Szily, E.; Kéri, S. Emotion-Related Brain Regions. Ideggyogy. Sz. 2008, 61, 77-86. 
100. Longo, M.R.; Azanon, E.; Haggard, P. More than skin deep: Body representation beyond primary somatosensory cortex. Neuropsychologia 2010, 48, 655-668. [CrossRef]

101. Kindler, S.; Schwahn, C.; Terock, J.; Mksoud, M.; Bernhardt, O.; Biffar, R.; Völzke, H.; Metelmann, H.R.; Grabe, H.J. Alexithymia and temporomandibular joint and facial pain in the general population. J. Oral Rehabil. 2018, 46, 310-320. [CrossRef]

102. Pinna, F.; Manchia, M.; Paribello, P.; Carpiniello, B. The Impact of Alexithymia on Treatment Response in Psychiatric Disorders: A Systematic Review. Front. Psychiatry 2020, 11, 311. [CrossRef]

103. Grabe, H.J.; Frommer, J.; Ankerhold, A.; Ulrich, C.; Gröger, R.; Franke, G.H.; Barnow, S.; Freyberger, H.J.; Spitzer, C. Alexithymia and Outcome in Psychotherapy. Psychother. Psychosom. 2008, 77, 189-194. [CrossRef] [PubMed]

104. Di Tella, M.; Castelli, L. Alexithymia in Chronic Pain Disorders. Curr. Rheumatol. Rep. 2016, 18, 1-9. [CrossRef] [PubMed]

105. Gündel, H.; Ceballos-Baumann, A.; Von Rad, M. Aktuelle Perspektiven der Alexithymie. Nervenarzt 2000, 71, 151-163. [CrossRef] [PubMed]

106. Derryberry, D.; Tucker, D.M. Neural mechanisms of emotion. J. Consult. Clin. Psychol. 1992, 60, 329-338. [CrossRef] [PubMed]

107. Gil, F.P.; Ridout, N.; Kessler, H.; Neuffer, M.; Schoechlin, C.; Traue, H.C.; Nickel, M. Facial emotion recognition and alexithymia in adults with somatoform disorders. Depress. Anxiety 2009, 26, E26-E33. [CrossRef]

108. Buhlmann, U.; Winter, A.; Kathmann, N. Emotion recognition in body dysmorphic disorder: Application of the Reading the Mind in the Eyes Task. Body Image 2013, 10, 247-250. [CrossRef]

109. Yetkin-Ozden, S.; Ekizoglu, E.; Baykan, B. Face Recognition in Patients with Migraine. Pain Pract. 2015, 15, 319-322. [CrossRef] [PubMed]

110. Flor, H. New developments in the understanding and management of persistent pain. Curr. Opin. Psychiatry 2012, 25, 109-113. [CrossRef]

111. Simons, L.E.; Elman, I.; Borsook, D. Psychological processing in chronic pain: A neural systems approach. Neurosci. Biobehav. Rev. 2014, 39, 61-78. [CrossRef]

112. Wolf, E.; Birgerstam, P.; Nilner, M.; Petersson, K. Nonspecific chronic orofacial pain: Studying patient experiences and perspectives with a qualitative approach. J. Orofac. Pain 2008, 22, 349-358.

113. Hazaveh, M.; Hovey, R. Patient Experience of Living with Orofacial Pain: An Interpretive Phenomenological Study. JDR Clin. Transl. Res. 2018, 3, 264-271. [CrossRef] [PubMed]

114. Bäck, K.; Hakeberg, M.; Wide, U.; Hange, D.; Dahlström, L. Orofacial pain and its relationship with oral health-related quality of life and psychological distress in middle-aged women. Acta Odontol. Scand. 2019, 78, 74-80. [CrossRef] [PubMed]

115. La Touche, R.; Pardo-Montero, J.; Gil-Martínez, A.; Paris-Alemany, A.; Angulo-Díaz-Parreño, S.; Suárez-Falcón, J.C.; Lara-Lara, M.; Fernandez-Carnero, J. Craniofacial pain and disability inventory (CF-PDI): Development and psychometric validation of a new questionnaire. Pain Physician 2014, 17, 95-108. [CrossRef]

116. Monticone, M.; Rocca, B.; Abelli, P.; Tecco, S.; Geri, T.; Gherlone, E.; Luzzi, D.; Testa, M. Cross-cultural adaptation, reliability and validity of the Italian version of the craniofacial pain and disability inventory in patients with chronic temporomandibular joint disorders. BMC Oral Health 2019, 19, 244. [CrossRef] [PubMed]

117. Greghi, S.M.; Aguiar, A.D.S.; Bataglion, C.; Ferracini, G.N.; La Touche, R.; Chaves, T. Brazilian Portuguese Version of the Craniofacial Pain and Disability Inventory: Cross-Cultural Reliability, Internal Consistency, and Construct and Structural Validity. J. Oral Facial Pain Headache 2018, 32, 389-399. [CrossRef] [PubMed]

118. Li, X.-L.; He, S.-L.; Wang, J.-H. Validation of a web-based version of the Craniofacial Pain and Disability Inventory. J. Oral Rehabil. 2020, 47, 802-808. [CrossRef] [PubMed]

119. Von Piekartz, H.; La Touche, R.; Paris-Alemany, A.; Löwen, A.; Ismail, M.; Köhl, R.; Benz, K.; Ballenberger, N. Cross-Cultural Adaption and Psychometric Evaluation of the German Craniofacial Pain and Disability Inventory (CF-PDI). Pain Physician 2020, in press.

120. Brähler, E.; Brosig, B.; Kupfer, J. Überprüfung und Validierung der 26-Item Toronto Alexithymie-Skala anhand einer repräsentativen Bevölkerungsstichprobe/Testing and validation of the 26-item Toronto Alexithymia Scale in a representative population sample. Z. Psychosom. Med. Psychother. 2000, 46, 368-384. [CrossRef] [PubMed]

121. La Touche, R.; Pardo-Montero, J.; Cuenca-Martínez, F.; Visscher, C.M.; Paris-Alemany, A.; López-De-Uralde-Villanueva, I. Cross-Cultural Adaptation and Psychometric Properties of the Spanish Version of the Tampa Scale for Kinesiophobia for Temporomandibular Disorders. J. Clin. Med. 2020, 9, 2831. [CrossRef] [PubMed]

122. He, S.; Wang, J.; Ji, P. Validation of the Tampa Scale for Kinesiophobia for Temporomandibular Disorders (TSK-TMD) in patients with painful TMD. J. Headache Pain 2016, 17, 1-5. [CrossRef] [PubMed]

123. Aguiar, A.S.; Bataglion, C.; Visscher, C.M.; Grossi, D.; Chaves, T.C. Cross-cultural adaptation, reliability and construct validity of the Tampa scale for kinesiophobia for temporomandibular disorders (TSK/TMD-Br) into Brazilian Portuguese. J. Oral Rehabil. 2017, 44, 500-510. [CrossRef] [PubMed]

124. Visscher, C.M.; Ohrbach, R.; Van Wijk, A.J.; Wilkosz, M.; Naeije, M. The Tampa Scale for Kinesiophobia for Temporomandibular Disorders (TSK-TMD). Pain 2010, 150, 492-500. [CrossRef]

125. Cameron, O.G. Interoception: The Inside Story-A Model for Psychosomatic Processes. Psychosom. Med. 2001, 63, 697-710. [CrossRef]

126. Craig, A.D. How do you feel? Interoception: The sense of the physiological condition of the body. Nat. Rev. Neurosci. 2002, 3, 655-666. [CrossRef] [PubMed] 
127. Fox, K.C.R.; Zakarauskas, P.; Dixon, M.; Ellamil, M.; Thompson, E.; Christoff, K. Meditation Experience Predicts Introspective Accuracy. PLoS ONE 2012, 7, e45370. [CrossRef]

128. Goyal, M.; Singh, S.; Sibinga, E.M.S.; Gould, N.F.; Rowland-Seymour, A.; Sharma, R.; Berger, Z.; Sleicher, D.; Maron, D.D.; Shihab, H.M.; et al. Meditation Programs for Psychological Stress and Well-being. JAMA Intern. Med. 2014, 174, 357-368. [CrossRef]

129. Barbero, M.; Moresi, F.; Leoni, D.; Gatti, R.; Egloff, M.; Falla, D. Test-retest reliability of pain extent and pain location using a novel method for pain drawing analysis. Eur. J. Pain 2015, 19, 1129-1138. [CrossRef] [PubMed]

130. Grashoff, M.; Klos, V. Reference Values of Facial Lateralization and Basic Emotions and Its Clinical Implementation in Chronic Facial Pain from the CRAFTA Face Recognition Program; University of Applied Science: Osnabruck, Germany, 2014.

131. Baron-Cohen, S.; Wheelwright, S.; Hill, J.; Raste, Y.; Plumb, I. The "Reading the Mind in the Eyes" Test revised version: A study with normal adults, and adults with Asperger syndrome or high-functioning autism. J. Child Psychol. Psychiatry 2001, 42, 241-251. [CrossRef]

132. Oakley, B.F.M.; Brewer, R.; Bird, G.; Catmur, C. Theory of mind is not theory of emotion: A cautionary note on the Reading the Mind in the Eyes Test. J. Abnorm. Psychol. 2016, 125, 818-823. [CrossRef] [PubMed]

133. Kessler, H.; Bayerl, P.; Deighton, R.M.; Traue, H.C. [Facially Expressed Emotion Labeling (FEEL): A Computer-Based Test for Emotion Recognition. Verhalt. Verhalt. 2002, 23, 297-306.

134. Von Piekartz, H.; Stotz, E.; Both, A.; Bahn, G.; Armijo-Olivo, S.; Ballenberger, N. Psychometric evaluation of a motor control test battery of the craniofacial region. J. Oral Rehabil. 2017, 44, 964-973. [CrossRef]

135. Mc Donnell, S.T.; Hector, M.P.; Hannigan, A. Chewing side preferences in children. J. Oral Rehabil. 2004, 31, 855-860. [CrossRef]

136. La Touche, R.; Losana-Ferrer, A.; Pascual-Vaquerizo, E.; Suso-Martí, L.; Paris-Alemany, A.; Chamorro-Sánchez, J.; CuencaMartínez, F. Orofacial sensorimotor behaviour in unilateral chewing: A comparative analysis in asymptomatic population. Physiol. Behav. 2019, 212, 112718. [CrossRef] [PubMed]

137. Adams, V.; Mathisen, B.; Baines, S.; Lazarus, C.; Callister, R. A Systematic Review and Meta-analysis of Measurements of Tongue and Hand Strength and Endurance Using the Iowa Oral Performance Instrument (IOPI). Dysphagia 2013, 28, 350-369. [CrossRef] [PubMed]

138. Zanin, M.C.; Garcia, D.M.; Rocha, E.M.; De Felício, C.M. Orofacial Motor Functions and Temporomandibular Disorders in Patients with Sjögren's Syndrome. Arthritis Rheum. 2019, 72, 1057-1065. [CrossRef] [PubMed]

139. Masalski, M.; Grysiński, T.; Kręcicki, T. Hearing Tests Based on Biologically Calibrated Mobile Devices: Comparison with Pure-Tone Audiometry. JMIR Mhealth Uhealth 2018, 6, e10. [CrossRef]

140. Kawakami, T.; Ishihara, M.; Mihara, M. Distribution Density of Intraepidermal Nerve Fibers in Normal Human Skin. J. Dermatol. 2001, 28, 63-70. [CrossRef]

141. Nolano, M.; Provitera, V.; Caporaso, G.; Stancanelli, A.; Leandri, M.; Biasiotta, A.; Cruccu, G.; Santoro, L.; Truini, A. Cutaneous innervation of the human face as assessed by skin biopsy. J. Anat. 2013, 222, 161-169. [CrossRef]

142. Khouri, L.; Nelken, I. Detecting the unexpected. Curr. Opin. Neurobiol. 2015, 35, 142-147. [CrossRef]

143. Gilbert, S.J.; Burgess, P.W. Executive function. Curr. Biol. 2008, 18, R110-R114. [CrossRef]

144. Glass, J.M.; Williams, D.A.; Fernandez-Sanchez, M.-L.; Kairys, A.; Barjola, P.; Heitzeg, M.; Clauw, D.J.; Schmidt-Wilcke, T. Executive Function in Chronic Pain Patients and Healthy Controls: Different Cortical Activation During Response Inhibition in Fibromyalgia. J. Pain 2011, 12, 1219-1229. [CrossRef]

145. Kieliba, P.; Clode, D.; Maimon-Mor, R.O.; Makin, T.R. Robotic hand augmentation drives changes in neural body representation Sci. Robot. 2021, 6, eabd7935. [CrossRef]

146. Moseley, L.G.; Wiech, K. The effect of tactile discrimination training is enhanced when patients watch the reflected image of their unaffected limb during training. Pain 2009, 144, 314-319. [CrossRef]

147. Coelho, L.A.; Gonzalez, C.L. The visual and haptic contributions to hand perception. Psychol. Res. 2017, 82, 866-875. [CrossRef]

148. Dagsdóttir, L.K.; Bellan, V.; Skyt, I.; Vase, L.; Baad-Hansen, L.; Castrillon, E.; Svensson, P. Multisensory modulation of experimentally evoked perceptual distortion of the face. J. Oral Rehabil. 2017, 45, 1-8. [CrossRef]

149. Essick, G.; Phillips, C.; Zuniga, J. Effect of Facial Sensory Re-training on Sensory Thresholds. J. Dent. Res. 2007, 86, 571-575. [CrossRef] [PubMed]

150. Moseley, L.G.; Zalucki, N.M.; Wiech, K. Tactile discrimination, but not tactile stimulation alone, reduces chronic limb pain. Pain 2008, 137, 600-608. [CrossRef]

151. Phillips, C.; Blakey, G.; Essick, G.K. Sensory Retraining: A Cognitive Behavioral Therapy for Altered Sensation. Atlas Oral Maxillofac. Surg. Clin. 2011, 19, 109-118. [CrossRef]

152. Galli, F.; Caputi, M.; Sances, G.; Vegni, E.; Bottiroli, S.; Nappi, G.; Tassorelli, C. Alexithymia in chronic and episodic migraine: A comparative study. J. Ment. Health 2016, 26, 192-196. [CrossRef] [PubMed]

153. Glaros, A.G.; Lumley, M.A. Alexithymia and pain in temporomandibular disorder. J. Psychosom. Res. 2005, 59, 85-88. [CrossRef] [PubMed]

154. Drimalla, H.; Landwehr, N.; Hess, U.; Dziobek, I. From face to face: The contribution of facial mimicry to cognitive and emotional empathy. Cogn. Emot. 2019, 33, 1672-1686. [CrossRef]

155. Carr, L.; Iacoboni, M.; Dubeau, M.-C.; Mazziotta, J.C.; Lenzi, G.L. Neural mechanisms of empathy in humans: A relay from neural systems for imitation to limbic areas. Proc. Natl. Acad. Sci. USA 2003, 100, 5497-5502. [CrossRef] 
156. Jeannerod, M.; Decety, J. Mental motor imagery: A window into the representational stages of action. Curr. Opin. Neurobiol. 1995, 5, 727-732. [CrossRef]

157. Schack, T.; Essig, K.; Frank, C.; Koester, D. Mental representation and motor imagery training. Front. Hum. Neurosci. 2014, 8, 328. [CrossRef] [PubMed]

158. Buccino, G. Action observation treatment: A novel tool in neurorehabilitation. Philos. Trans. R. Soc. B Biol. Sci. 2014, $369,20130185$. [CrossRef] [PubMed]

159. Decety, J. The neurophysiological basis of motor imagery. Behav. Brain Res. 1996, 77, 45-52. [CrossRef]

160. Moseley, L.G. Graded motor imagery is effective for long-standing complex regional pain syndrome: A randomized controlled trial. Pain 2004, 108, 192-198. [CrossRef] [PubMed]

161. Moseley, G.L. Graded motor imagery for pathologic pain: A randomized controlled trial. Neurology 2006, 67, 2129-2134. [CrossRef]

162. La Touche, R. Métodos de representación del movimiento en rehabilitación. Construyendo un marco conceptual para la aplicación en clínica. J. MOVE Ther. Sci. 2020, 2, 7. [CrossRef]

163. Amesz, S.; Tessari, A.; Ottoboni, G.; Marsden, J. An observational study of implicit motor imagery using laterality recognition of the hand after stroke. Brain Inj. 2016, 30, 1-6. [CrossRef]

164. Hardwick, R.M.; Caspers, S.; Eickhoff, S.B.; Swinnen, S.P. Neural correlates of action: Comparing meta-analyses of imagery, observation, and execution. Neurosci. Biobehav. Rev. 2018, 94, 31-44. [CrossRef] [PubMed]

165. Wang, J.; Fritzsch, C.; Bernarding, J.; Holtze, S.; Mauritz, K.; Brunetti, M.; Dohle, C. A comparison of neural mechanisms in mirror therapy and movement observation therapy. J. Rehabil. Med. 2013, 45, 410-413. [CrossRef]

166. Zhang, Y.; Zhang, W.; Xing, B.; Li, J.; Yang, C.; Han, C.; Wang, Q. Mirror Therapy Versus Action Observation Therapy: Effects on Excitability of the Cerebral Cortex in Patients after Strokes. Int. J. Clin. Exp. Med. 2019, 12, 8763-8772.

167. Suso-Martí, L.; La Touche, R.; Díaz-Parreño, S.A.; Cuenca-Martínez, F. Effectiveness of motor imagery and action observation training on musculoskeletal pain intensity: A systematic review and meta-analysis. Eur. J. Pain 2020, 24, 886-901. [CrossRef] [PubMed]

168. Thieme, H.; Morkisch, N.; Rietz, C.; Dohle, C.; Borgetto, B. The Efficacy of Movement Representation Techniques for Treatment of Limb Pain-A Systematic Review and Meta-Analysis. J. Pain 2016, 17, 167-180. [CrossRef] [PubMed]

169. Da Yap, B.W.; Lim, E.C.W. The Effects of Motor Imagery on Pain and Range of Motion in Musculoskeletal Disorders. Clin. J. Pain 2019, 35, 87-99. [CrossRef]

170. Paravlic, A.H.; Slimani, M.; Tod, D.; Marusic, U.; Milanovic, Z.; Pisot, R. Effects and Dose-Response Relationships of Motor Imagery Practice on Strength Development in Healthy Adult Populations: A Systematic Review and Meta-analysis. Sports Med. 2018, 48, 1165-1187. [CrossRef] [PubMed]

171. La Touche, R.; Grande-Alonso, M.; Cuenca-Martínez, F.; Gónzález-Ferrero, L.; Suso-Martí, L.; Paris-Alemany, A. Diminished Kinesthetic and Visual Motor Imagery Ability in Adults with Chronic Low Back Pain. PMER 2019, 11, 227-235. [CrossRef]

172. Monsma, E.V.; Short, S.E.; Hall, C.R.; Sullivan, P.; Gregg, M. Psychometric Properties of the Revised Movement Imagery Questionnaire (MIQ-R). J. Imag. Res. Sport Phys. Act. 2009, 4, 4. [CrossRef]

173. Hidalgo-Peréz, A.; Fernández-García, Á.; López-De-Uralde-Villanueva, I.; Gil-Martínez, A.; Paris-Alemany, A.; FernandezCarnero, J.; La Touche, R. Effectiveness of A Motor Control Therapeutic Exercise Program Combined with Motor Imagery on the Sensorimotor Function of the Cervical Spine: A Randomized Controlled Trial. Int. J. Sports Phys. Ther. 2015, 10, 877-892. [PubMed]

174. Daly, A.E.; Bialocerkowski, A.E. Does evidence support physiotherapy management of adult Complex Regional Pain Syndrome Type One? A systematic review. Eur. J. Pain 2009, 13, 339-353. [CrossRef] [PubMed]

175. La Touche, R.; Herranz-Gómez, A.; Destenay, L.; Gey-Seedorf, I.; Cuenca-Martínez, F.; Paris-Alemany, A.; Suso-Martí, L. Effect of brain training through visual mirror feedback, action observation and motor imagery on orofacial sensorimotor variables: A single-blind randomized controlled trial. J. Oral Rehabil. 2020, 47, 620-635. [CrossRef] [PubMed]

176. Krämer, H.H.; Seddigh, S.; Moseley, G.L.; Birklein, F.; Moseley, L. Dysynchiria is not a common feature of neuropathic pain. Eur. J. Pain 2008, 12, 128-131. [CrossRef]

177. Breckenridge, J.D.; Ginn, K.A.; Wallwork, S.B.; McAuley, J.H. Do People with Chronic Musculoskeletal Pain Have Impaired Motor Imagery? A Meta-analytical Systematic Review of the Left/Right Judgment Task. J. Pain 2019, 20, 119-132. [CrossRef]

178. Essick, G.; Afferica, T.; Aldershof, B.; Nestor, J.; Kelly, D.; Whitsel, B. Human perioral directional sensitivity. Exp. Neurol. 1988, 100, 506-523. [CrossRef]

179. Gülbetekin, E.; Altun, E.; Er, M.N.; Fidanc1, A.; Keskin, P.; Steenken, D. Effects of right or left face stimulation on self and other perception in enfacement illusion. Soc. Neurosci. 2021, 16, 1-17. [CrossRef]

180. Wittkopf, P.; Lloyd, D.; Johnson, M. The effect of visual feedback of body parts on pain perception: A systematic review of clinical and experimental studies. Eur. J. Pain 2018, 22, 647-662. [CrossRef]

181. Sessle, B.; Adachi, K.; Avivi-Arber, L.; Lee, J.; Nishiura, H.; Yao, D.; Yoshino, K. Neuroplasticity of face primary motor cortex control of orofacial movements. Arch. Oral Biol. 2007, 52, 334-337. [CrossRef]

182. Brunsdon, V.E.A.; Bradford, E.E.F.; Smith, L.; Ferguson, H.J. Short-term physical training enhances mirror system activation to action observation. Soc. Neurosci. 2019, 15, 98-107. [CrossRef]

183. Kawai, N.; Shibata, M.; Watanabe, M.; Horiuchi, S.; Fushima, K.; Tanaka, E. Effects of functional training after orthognathic surgery on masticatory function in patients with mandibular prognathism. J. Dent. Sci. 2020, 15, 419-425. [CrossRef] [PubMed] 
184. Greene, D.L.; Appel, A.J.; Reinert, S.E.; Palumbo, M.A. Lumbar Disc Herniation. Spine 2005, 30, 826-829. [CrossRef]

185. Nijs, J.; Roussel, N.; van Wilgen, C.P.; Köke, A.; Smeets, R. Thinking beyond muscles and joints: Therapists' and patients' attitudes and beliefs regarding chronic musculoskeletal pain are key to applying effective treatment. Man. Ther. 2013, 18, 96-102. [CrossRef]

186. Moseley, G.L.; Nicholas, M.K.; Hodges, P. Does anticipation of back pain predispose to back trouble? Brain 2004, 127, 2339-2347. [CrossRef]

187. Nijs, J.; van Wilgen, C.P.; Van Oosterwijck, J.; van Ittersum, M.; Meeus, M. How to explain central sensitization to patients with 'unexplained' chronic musculoskeletal pain: Practice guidelines. Man. Ther. 2011, 16, 413-418. [CrossRef] [PubMed]

188. Louw, A.; Zimney, K.; Puentedura, E.J.; Diener, I. The efficacy of pain neuroscience education on musculoskeletal pain: A systematic review of the literature. Physiother. Theory Pract. 2016, 32, 332-355. [CrossRef]

189. Marcos-Martín, F.; González-Ferrero, L.; Martín-Alcocer, N.; Paris-Alemany, A.; La Touche, R. Multimodal physiotherapy treatment based on a biobehavioral approach for patients with chronic cervico-craniofacial pain: A prospective case series. Physiother. Theory Pract. 2018, 34, 671-681. [CrossRef] [PubMed]

190. Turk, D.C.; Wilson, H.D. Fear of Pain as a Prognostic Factor in Chronic Pain: Conceptual Models, Assessment, and Treatment Implications. Curr. Pain Headache Rep. 2010, 14, 88-95. [CrossRef]

191. Bromberg, J.; Wood, M.E.; Black, R.A.; Ba, D.A.S.; Zacharoff, K.L.; Chiauzzi, E.J. A Randomized Trial of a Web-Based Intervention to Improve Migraine Self-Management and Coping. Headache J. Head Face Pain 2012, 52, 244-261. [CrossRef] [PubMed] 